\title{
Synaptic Organization of Individual Neurons in the Macaque Lateral Geniculate Nucleus
}

\author{
James R. Wilson \\ Yerkes Regional Primate Research Center, and Departments of Anatomy/Cell Biology and Ophthalmology, Emory \\ University, Atlanta, Georgia 30322
}

Parvocellular and magnocellular neurons in the dorsal lateral geniculate nucleus of macaque monkeys were recorded electrophysiologically and then injected with HRP. The injected neurons were examined with the electron microscope. Synaptic terminals contacting the dendrites of individual neurons were classified and the synapses counted to estimate the number and distribution of each type over the entire dendritic tree.

Seven parvocellular and 2 magnocellular neurons were analyzed. Two of the parvocellular neurons had presynaptic dendrites and no axons. These interneurons had electrophysiological characteristics much like those of relay neurons with the exception that their receptive field center responses had the opposite sign; i.e., they had off centers, while most neurons around them had on centers.

All of the relay neurons had similar types and distributions of terminal contacts. However, the distribution of each synaptic type along the dendrites of an individual neuron was not homogeneous. Retinal and $F$ terminals were located predominantly on proximal dendrites whereas RSD terminals, either from the cortex and/or brain stem, predominated on the intermediate and distal dendrites. Parvocellular neurons were estimated to have about 500 total synapses on their dendritic trees, while magnocellular neurons had about $\mathbf{3 0 0 0}$ total synapses on their dendritic trees. The retinal terminals making synaptic contacts with magnocellular neurons were also presynaptic to terminals containing flattened vesicles; these latter terminals also had synapses onto the magnocellular neuron's dendrites. Such a synaptic arrangement is called a triadic arrangement, or triad. Parvocellular neurons rarely had such triadic arrangements.

In comparing these data with those of the cat, it was concluded that the major synaptic difference between relay cell types in both species (Class 1/Class 2 cells for the cat and parvo/magno cells for the monkey) was the frequent occurrence of triads for Class 2 cells and magnocellular cells versus the infrequent occurrence of triads for Class 1 cells and parvocellular cells. Although these triadic arrangements have been studied for over 2 decades, their function has yet

\footnotetext{
Received Oct. 31, 1988; revised Jan. 23, 1989; accepted Jan. 30, 1989.

This research was supported by NIH grants EY04976 and RR00165. I thank Ms. Patricia Fincher for her expert technical assistance in the electron microscopic preparations and the many people who critiqued the manuscript. I also thank the veterinaries and their staff at Yerkes Research Center for the animal care. Yerkes Regional Primate Research Center is fully accredited by the American Association for Accreditation of Laboratory Animal Care

Correspondence should be addressed to Jim Wilson at the above address.

Copyright (C) 1989 Society for Neuroscience 0270-6474/89/082931-23\$02.00/0
}

to be determined, but probably relates to inhibition of retinal signals at dendrites of magnocellular neurons in the monkey and Class 2 cells in the cat.

Information about the source of afferents to the lateral geniculate nucleus (LGN), termination sites of those afferents, and their interneuronal connections are all prerequisites for interpreting physiological data and for establishing better models of function for this sensory nucleus. Known afferents to the monkey's LGN include retinal ganglion cell axons as the primary sensory input and a large cortical feedback from areas 17, 18, and MT (e.g., Spatz et al., 1970; Lin and Kaas, 1977). The synaptic sites of these afferents on individual dendrites have previously been characterized by observations with the electron microscope (EM) of single thin sections or a short series of thin sections (e.g., Guillery and Colonnier, 1970; Winfield, 1980). However, the distributions of different afferent types and their total number onto the dendritic trees of single neurons could not be directly determined with these methods.

Afferents to the monkey's LGN also arise from the brain stem, but the specific nuclei supplying these afferents, their morphology, density, and sites of termination, including their postsynaptic structures, and their physiological significance have been studied relatively little (e.g., Singer, 1977; Burke and Cole, 1978, for reviews of earlier publications, see Harting et al., 1978, 1986; Morrison and Foote, 1986; Wilson and Hendrickson, 1988).

Local circuit neurons or interneurons are believed to provide the major inhibitory terminals that are critically important to the function of the LGN, and while some of their anatomical characteristics have been studied, their physiological properties are unknown for the monkey. Estimates of the percentage of interneurons in the monkey's LGN range from $1-25 \%$ in the parvoccllular laminae and 3-35\% in the magnocellular laminae (Norden and Kaas, 1978; Hámori et al., 1983; Hendrickson et al., 1983; Montero and Zempel, 1986). The output connections of interneurons appear to be by way of terminals from presynaptic dendrites and local axons (Hámori et al., 1975, 1978; Montero, 1987). These terminals have flattened or pleomorphic vesicles, contain GABA as their transmitter, and are almost certainly inhibitory to their postsynaptic targets (see Hendrickson et al., 1983).

Considerably more data are available on the electrophysiological and light microscopic properties of relay neurons in the LGN. In particular, LGN relay neurons in the monkey can be separated into the major catagories of magnocellular and parvocellular types (Clark, 1932; Kaas et al., 1978). The primary physiological differences between the 2 types are the high contrast sensitivies, broad-band spectral responses, fast axonal con- 
duction velocities, and phasic responses of magnocellular cells compared with parvocellular cells, which have low contrast sensitivities, narrow-band spectral tuning, slower axonal conduction velocities, and generally tonic responses to appropriate stimuli (Marrocco and Brown, 1975; Dreher et al., 1976; Marrocco, 1976; Sherman et al., 1976; Lee et al., 1979; Blakemore and Vital-Durand, 1981, 1986; Marrocco et al., 1982; Derrington and Lennic, 1984; Shaplcy and Pcrry, 1986). Cells of the LGN can also be divided physiologically into on and ofF center types. These types have an anatomical separation for the parvocellular neurons in that the on center cells are located mostly in laminae 5 and 6 and the ofF center cells are located mostly in laminae 3 and 4 (Schiller and Malpeli, 1978). Magnocellular ON and OFF cells are intermixed in laminae 1 and 2. An important physiological difference has been observed for magnocellular neurons in terms of their linear or nonlinear responses to grating patterns (Blakemore and Vital-Durand, 1981; Shapley et al., 1981), but it is currently unknown if this difference has a morphological correlate in the LGN. In Galago, 2 of the laminae and the interlaminar zones contain a further physiological class of neuron with very heterogeneous properties (Norton and Casagrande, 1982; Irwin et al., 1986). Theses neurons probably correspond to neurons in the intercalated and $\mathrm{S}$ laminae of other monkeys (Fitzpatrick et al., 1983; Weber et al., 1983). Several further physiological classifications can be made for monkey LGN neurons, but there are little or no data on their anatomical correlates, and some of the classes probably relate to differences determined in the retina rather than being related to LGN circuitry (e.g., Wiesel and Hubel, 1966; DeValois et al., 1967; Abramov, 1968; DeMonasterio and Gouras, 1975; Gielen et al., 1981).

In order to study the physiology, morphology, and connections of neurons in the cat's LGN, Friedlander et al. (1981) used the method of intracellular injection of HRP. With this technique, a neuron could be recorded electrophysiologically and then the soma and entire dendritic tree of the same neuron studied with light microscopy. Furthermore, this method provided the distinct advantage of allowing the neuron to be examined at the EM level. Thus, the synaptic inputs to an individual neuron that had been studied physiologically could be determined. Because many of the presynaptic terminals in the LGN could be identified at the EM level without specific labeling, their number and distribution onto different types of neurons could be studied. This method has been previously used to examine the microcircuitry of the cat's LGN (Wilson et al., 1984). The purpose of the present study was to carry out a similar analysis in the monkcy's LGN. A short report of some of these data has been published previously (Wilson, 1986).

\section{Materials and Methods}

Physiology. Each of the 7 monkeys (Macaca mulatta) was initially anesthetized with an intramuscular injection of ketamine $(15 \mathrm{mg} / \mathrm{kg})$. An anesthetic dose of pentobarbital (30-60 mg) was then given through a venous cannulation tube followed by continuous infusion of $5 \%$ dextrose in Ringer's solution. A tracheotomy was performed to allow artificial respiration when the monkey was paralyzed with gallamine triethiodide. The paralytic continued to be given at $10-20 \mathrm{mg} / \mathrm{hr}$ in the infusion solution throughout the experiment. Respiration rates and volumes were adjusted to produce a $4.5-5.0 \% \mathrm{CO}_{2}$ level at the tracheal tube as measured breath-by-breath with a $\mathrm{CO}_{2}$ monitor. A mixture of $\mathrm{N}_{2} \mathrm{O}$ and $\mathrm{O}_{2}$ $(75 \%: 25 \%)$ was used as the inspired gas. Heart rate, rectal temperature, and blood pressure were all continuously monitored. With the head in a stereotaxic holder, a cranial opening $10 \mathrm{~mm}$ in diameter was made by a trephine over the estimated position of the LGN. After surgery, the level of anesthesia was adjusted with additional pentoharbital (1-3 $\mathrm{mg} / \mathrm{kg}-\mathrm{hr}$ ) for the remainder of the experiment such that no heart rate change occurred following a finger pinch.

To prevent the corneas from drying out and to focus the eyes on a tangent screen, contact lenses were placed on the eyes. The radii of these lenses were chosen to focus stimuli located at a distance of $171 \mathrm{~cm}$ onto the retinae. Additional corrective lenses in front of the eyes were used when slit retinoscopy indicated that the images would be more than one diopter out of focus.

Beveled glass microelectrodes were lowered into the brain through a guide tube to record electrical potentials from LGN neurons. The micropipettes contained $4 \% \mathrm{HRP}$ in a $\mathrm{KCl}$ and trisma buffer solution (pH 7.4). A plastic cap was cemented around the cranial hole to provide a chamber in which warm agar could be poured around the electrode. Hot wax was poured on top of the cooled agar. This achieved a hydraulic seal for the craniotomy to reduce pulsations. An intracellular amplifier provided both DC and filtered AC standard recording signals to an oscilloscope and audio monitor.

Once the action potentials from a neuron were picked up and isolated, the waveform was noted. Somata recordings with these electrodes generally had biphasic waveforms with a change in the rising slope between the initial segment and the soma/dendritic response (IS-SD break), while axons had monophasic waveforms with a rapid rise time (Bishop et al., 1962). The receptive field of each neuron was plotted on the tangent screen with small spots of light. Characteristics measured or noted for each neuron were (1) latency to optic chiasm stimulation, (2) eye dominance, (3) approximate color preference for the receptive field center (red, green, or blue), (4) phasic or tonic responses, and (5) linear or nonlinear responses to a grating pattern. Grating patterns were generated on a 603 Tektronic or $1332 \mathrm{~A}$ Hewlett-Packard monitor oscilloscope. The patterns were counterphase-modulated at $2 \mathrm{~Hz}$ over several spatial frequencies near the maximum resolution of the neurons. The responses were audibly checked for frequency doubling (nonlinear $=$ response at each phase change) or fundamental responses (linear $=$ response only to alternate phase changes and a null point; Shapley et al., 1981). Detailed analysis of responses to colored stimuli were not carried out due to time considerations. Thus, morphological correlations with physiological classifications based on responses to color could not be made.

After obtaining as many of these data as commensurate with stability of the recording for each neuron, the microelectrode was advanced in rapid steps of $2-4 \mu \mathrm{m}$ with a Burleigh Inchworm Drive coupled with 1-2 nA of positive current pulses to penetrate the neural membrane. Such penetrations were revealed by a voltage drop on the DC recording trace of $10-50 \mathrm{mV}$. Once penetrated, the receptive field center was rechecked for its position and response along with the latency to optic chiasm stimulation to verify that the electrode had entered the neuron that had previously been extracellularly characterized. HRP was then iontophoresed into the neuron over a $1-10 \mathrm{~min}$ period with 4-8 $\mathrm{nA}$ pulses of positive square-wave current $(300 \mathrm{msec})$ from a $90 \mathrm{~V}$ battery integrated into the circuitry of the intracellular amplifier. Actual current passing through the tip was measured by a special circuit that operated separate from the recording circuitry. If the DC level rose to the original baseline at any time, the iontophoresis was halted and the electrode moved to a new lamina or retinotopic location.

Histology. Upon completion of the HRP injections, the monkey was deeply anesthetized and perfused transcardially with a buffered phosphate solution containing $1 \%$ paraformaldehyde, $2 \%$ gluteraldehyde, and 5\% sucrose. The LGN was blocked out and placed in buffer overnight. The next day the block was sectioned into $50-\mu \mathrm{m}$-thick pieces in a coronal plane with a Vibratome. These sections were treated with either diaminobenzidine or a Hanker-Yates procedure (Hanker et al., 1977). Each section was then wet-mounted on a slide with buffer solution and examined for HRP-filled neurons. Sections containing such neurons were further processed for electron microscopy by osmication, dehydration, and embedding in Epon 812.

A drawing of each HRP-filled soma and all of its dendrites was made using a light microscope with a camera lucida attachment. Usually, the $50-\mu \mathrm{m}$-thick section containing the soma also contained numerous proximal, intermediate, and distal dendrites. This tissue was further cut with an ultramicrotome into serial sections about $80 \mathrm{~nm}$ thick and picked up on Formvar-coated slotted grids. Every 4th section (or 5th section in initial cases) was stained with uranyl acetate and lead citrate and examined with a Zeiss S9 electron microscope. Adjacent sections were stained and checked for questionable synapses.

All pieces of HRP-filled dendrites with synapses on them were pho- 
Table 1. Summary of the number of HRP-filled neurons observed in each lamina of the rhesus monkey's dLGN and as grouped by receptive field center response (on or ofF)

\begin{tabular}{lll} 
& \multicolumn{2}{l}{ Center response } \\
\cline { 2 - 3 } Lamina & ON & OFF \\
\hline 6 & 8 & 1 \\
5 & 2 & 1 \\
4 & 0 & 4 \\
3 & 0 & 3 \\
2 & 4 & 1 \\
1 & 0 & 1 \\
\hline
\end{tabular}

tographed at a magnification of $8500 \times$. The negatives were printed at a final magnification of $25,500 \times$ to allow identification of the terminal types making synaptic contacts with the dendrites. The dendrites remaining in the uncut part of the thick section were redrawn after every 24 th thin section. This helped to pinpoint the site of the synapses onto the pieces of dendrites that had just been cut in the previous 24 sections.

In order to determine the number of synapses that might be missed by observing every 4th section instead of complete serial reconstructions, a sample of an additional neuron's dendritic tree was checked for synapses both in serial sections and observing every 4th section. This procedure showed that only synapses related to terminals with flattened vesicles ( $\mathrm{F}$ type) were underestimated (see Results).

\section{Results}

Physiology

Over the course of this study, 25 neurons in the LGN were recorded electrophysiologically, injected with HRP, and recovered after reacting the sections. Table 1 lists the lamina in which each soma was located and its center response, oN or OFF. This table supports the results of Schiller and Malpeli (1978), who found that most parvocellular on center neurons were lo- cated in the dorsal 2 lamina (laminae 5 and 6), and most parvocellular ofF center neurons were located in the ventral 2 parvocellular laminae (laminae 3 and 4). The significant exceptions to this separation are 2 ofF center neurons in laminae 5 and 6 which will be shown to be interneurons (see below). The emphasis of this paper will be on 9 neurons that were examined with the electron microscope. Seven of these were relay neurons and 2 were interneurons.

Table 2 lists the properties of each of the 9 neurons used for EM cxaminations. Also shown are 3 additional, linearly responding magnocellular neurons to compare with the nonlinear magnocellular cell (cell 33-69). Figures 1-3 are drawings of all of these neurons. The first 7 had somata located in the parvocellular laminae (laminae 3-6). These had typical receptive fields whose centers responded best to colored stimuli. Latencies to optic chiasm stimulation were in the $2-4 \mathrm{msec}$ range as expected for the medium conduction speeds of their afferents.

Cells 12-28 and 36-93, also located in the parvocellular laminae, did not appear to be unusual in most of their electrophysiological properties when they were recorded and injected, even though they had ofF center responses; i.e., some cells were expected to have ofF center responses in the upper 2 laminae (Schiller and Malpeli, 1978). However, they were later found to have distinct light and EM morphologies identifying them as interneurons. These morphological details are provided in a later section. Two further electrophysiological properties were of interest post hoc for these neurons. First, cell 12-28 had an on response to a blue screen of a colored television monitor. There was no response to the yellow, red, green, or black colors also being flashed consecutively on the screen. The screen was centrally located in the visual field far from the cell's receptive field center, which was in the far periphery. This observation was fortuitious because this result was not derived from a procedure normally used to test the cells. Since there were no other

Table 2. Summary of pertinent data from HRP-filled neurons of the monkey's dLGN

\begin{tabular}{|c|c|c|c|c|c|c|c|}
\hline \multirow[b]{2}{*}{ Cell } & \multirow[b]{2}{*}{ Lam. } & \multirow{2}{*}{$\begin{array}{l}\text { Center } \\
\text { response }\end{array}$} & \multirow{2}{*}{$\begin{array}{l}\text { Center } \\
\text { size } \\
\text { (deg) } \\
\end{array}$} & \multicolumn{2}{|c|}{$\begin{array}{l}\text { Coordinates } \\
\text { (deg) }\end{array}$} & \multirow{2}{*}{$\begin{array}{l}\text { Optic } \\
\text { chiasm } \\
\text { latency } \\
\text { (msec) }\end{array}$} & \multirow[b]{2}{*}{ Other } \\
\hline & & & & Azim. & Elev. & & \\
\hline $8-28$ & 3 & OFF & 0.5 & 2 & 2 & $3.0-3.5$ & Red \\
\hline $17-31$ & 4 & OFF & $*$ & 37 & 0 & $3.3-3.5$ & Red and green \\
\hline $21-54$ & 6 & $\mathrm{ON} / \mathrm{OFF}$ & 0.8 & 7 & -6 & - & ON green; OFF red \\
\hline $21-66$ & 6 & ON & 0.3 & 10 & -7 & - & Red and green \\
\hline $23-53$ & 6 & ON & 0.4 & 7 & -2 & $2.7-3.0$ & Red and white \\
\hline $12-28$ & $4 / 6$ & OFF & 2.0 & 44 & -9 & $2.4-2.7$ & White $^{a}$ \\
\hline $36-93$ & 5 & OFF & 0.5 & 2 & 7 & 4.0 & $b$ \\
\hline $17-65$ & 2 & ON & $*$ & 27 & -7 & $1.4-1.5$ & Linear \\
\hline $33-69$ & 2 & OFF & $*$ & 2 & -2 & $1.7-1.9$ & Nonlinear \\
\hline $29-25$ & 2 & ON & 0.6 & 1 & 1 & $1.6-1.7$ & Linear \\
\hline $36-55$ & 2 & ON & 1.1 & 18 & 10 & $1.3-1.5$ & Linear \\
\hline $36-87$ & 2 & OFF & 0.5 & 5 & 4 & $1.7-1.9$ & Linear \\
\hline
\end{tabular}

The top 9 cells were used for electron microscopy. Because 3 of the cells $\left(^{*}\right)$ had poor recording stability, the receptive field centers were not accurately plotted prior to the injections. Azim., azimith; Elev., elevation: coordinates in the visual field for the receptive field center. Optic chiasm latencies are the range for the measurements made from the OX shock to the initial foot of the action potential of the dLGN cell. "Other" category shows the color to which the parvocellular neurons had excitatory responses and the counterphase-modulated grating responses for magnocellular neurons.

"This cell had an on center response to a large blue stimulus $\left(10^{\circ} \times 10^{\circ} \mathrm{RGB}\right.$ monitor screen) $25^{\circ}$ from the receptive field center.

${ }^{b}$ An on center cell was simultaneously recorded extracellularly and its receptive field center was next to that of this neuron's center. 
cells to compare it against in this regard, this is simply a point of information. Second, during the extracellular part of the recording procedures for cell 36-93, another cell's action potentials were also picked up. The second cell had an on center receptive field that was located next to the receptive field center of the OFF cell. Thus, the OFF center cell (cell 36-93) had its center in the surround of the oN center cell. This may have significance in terms of the functional aspects of the ofF center interneuron (see Discussion).

The last 5 cells in Table 2 were located in magnocellular lamina 2, and their latencies to optic chiasm stimulation reflected the fast conduction speeds of their retinal inputs. Recording stability was generally poor for the neurons located in the ventral laminae of the LGN. Therefore, little time was spent on mapping the receptive fields other than to determine their positions, center responses to white light, and sometimes their size. A property considered to be more important was their response to a grating pattern. Cell 33-69 had doubling responses to the counterphased modulated grating pattern and was classified as nonlinear. 'The remaining 4 cells had only a fundamental response at any spatial frequency tested and were thus considcred to be lincar.

\section{Morphology}

\section{Relay neurons}

\section{LIGHT MICROSCOPY}

Neurons that had an axon leaving the LGN were considered to be relay cells. All of these relay neurons had HRP extending 4$6 \mathrm{~mm}$ along their axons. Each axon eventually reached the optic radiations (but not the pregeniculate nucleus) before the HRP faded out. Only one axon was observed to have an intrageniculate collateral branch. This axon was from cell 17-65 whose soma was located in lamina 2 . The parent axon initially coursed ventrally, and the collateral came off near its most ventral point. The collateral went into lamina 1 , where it faded out near the ventral border of the LGN. The parent axon turned and exited near the posterior pole of the LGN.

The soma sizes and dendritic patterns of the relay neurons were not different from those previously described with Golgi staining techniques (Figs. 1, 2; e.g., Saini and Garey, 1981; Wilson and Hendrickson, 1981). That is, the dendrites of the relay neurons from the parvocellular and magnocellular laminae generally radiated out from the somata and occasionally showed some orientation preference. Most of the dendrites ended 100 $200 \mu \mathrm{m}$ from the soma center with only a few reaching further than $200 \mu \mathrm{m}$. The HRP continued to fill the dendrites to their termination point, so all of the dendritic tree was visualized from the injection. Some dendrites crossed laminar borders and reached short distances into other laminae. The magnocellular neurons typically had more dendrites and more branch points, resulting in total dendritic lengths greater than those of the parvocellular neurons. Neuron 17-65 was an exception in having short dendrites with a cumulative total length more in the parvocellular range (Fig. 2, Table 3). Neuron 33-69 is typical of the magnocellular neurons, and its data (Table 3) are probably more represcntative than the data of neuron 17-65. Three other magnocellular neurons that were not examined with the electron microscope are drawn in Figure 2. These had linear responses to grating patterns and are shown to emphasize that linear cells could also have large dendritic trees like that observed for the nonlinear cell (cell 33-69).

\section{ELECTRON MICROSCOPY}

Terminal types. The terminals associated with synapses in the LGN can be grouped into 3 major types, each of which has distinctive features by current EM techniques of fixation. Guillery and Colonnier (1970) provided the currently used classification of these types nearly 20 years ago.

The first type of terminal is one which contains loosely distributed round vesicles, is relatively large in size and has pale mitochondria (RLP type; Fig. $4 B$ ). From degeneration and autoradiographic studies, these terminals are known to originate from retinal ganglion cells (Colonnier and Guillery, 1964; PecciSaavedra et al., 1968; LeVay, 1971; Hendrickson, 1972; WongRiley, 1972). The second type of terminal also has round vesicles, is relatively small in size, and, when mitochondria are present, they are dark (RSD type; Fig. 4C). Many of these terminals arc dcrived from cortical areas (Szentágothai et al., 1966; Jones and Powell, 1969; Winfield et al., 1975). The remainder are probably from brain-stem nuclei (Robson and Hall, 1977; Torrealba et al., 1981; Weber and Kalil, 1987) and may have characteristics somewhat different from RSD (deLima et al., 1985; Cucchiaro et al., 1988) but would have been included in this category for this study. The third major type of terminal ( $F$ lype) is mainly characterized by the shape of its synaptic vesicles (Fig. 4B). These can be described as flattened or pleomorphic. These terminals are generally of medium size and have been demonstrated to contain GABA (Hendrickson et al., 1983; Montero, 1986b). F terminals can many times be subtyped into F1 and F2 categories (Guillery, 1969; LeVay, 1971; Wong-Riley, 1972; Hámori et al., 1974). In these cases, F1 terminals have flatter vesicles within a darker cytoplasmic matrix and several dark mitochondria and are always presynaptic. F2 terminals have synaptic vesicles that are more variable in size and shape and generally do not fill the terminal. Also, the cytoplasmic matrix is lighter, and mitochondria are frequently absent. F2 terminals can be presynaptic to dendrites and postsynaptic to F1, RLP, RSD, and sometimes to other F terminals. The F terminals originate from 3 possible sources: dendrites of LGN interneurons (F2 or ID: Wong, 1970; Famiglietti and Peters, 1972; Lieberman, 1973; Hámori et al., 1975; Hamos et al., 1985), axons of interneurons (Montero, 1987), and axons from neurons in the thalamic reticular nucleus (F1: Ohara et al., 1980; Montero and Scott, 1981).

In addition to these major types of terminals, there are other, infrequently observed, terminal types in the LGN (Pasik et al., 1986). These include the RMD type observed in monkey (round vesicles, medium size, and dark mitochondria; Wilson and Hendrickson, 1981; Figs. 4D, 7D) and several others observed in cat (see Famiglietti and Peters, 1972; Montero, 1987; Cucchiaro et al., 1988).

The synapses made by the 3 major terminal types are typically described as asymmetrical (RLP, RSD) or symmetrical (F types). However, not all synapses clearly fall into one category or the other, and thus the synapse alone cannot be used for categorizing terminal types (Wong-Riley, 1972; Rapisardi and Lipsenthal, 1984). Indeed, some terminals appear to have no synapses associated with them at all (5-HT terminals; Wilson and Hendrickson, 1988).

HRP-filled neurons. The reaction product obtained from diaminobenzidine or Hanker-Yates procedures is electron dense so that somata, dendrites, and axons containing HRP in thin 

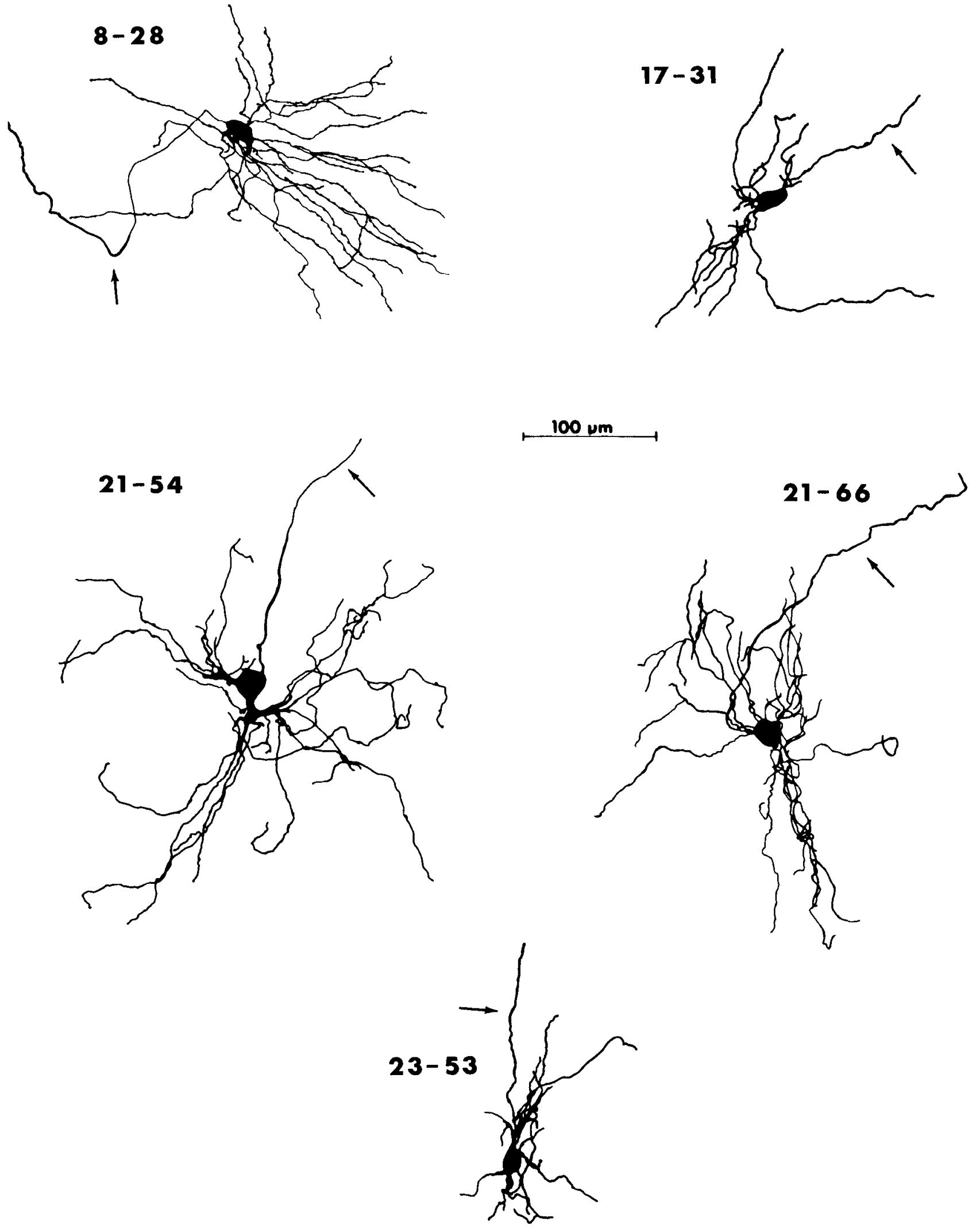

Figure 1. Drawings of parvocellular relay neurons that were filled with HRP in the monkey's LGN and analyzed with the electron microscope for synaptic inputs. Properties are listed in Table 2 for each neuron. Arrows indicate the axon for each neuron. 

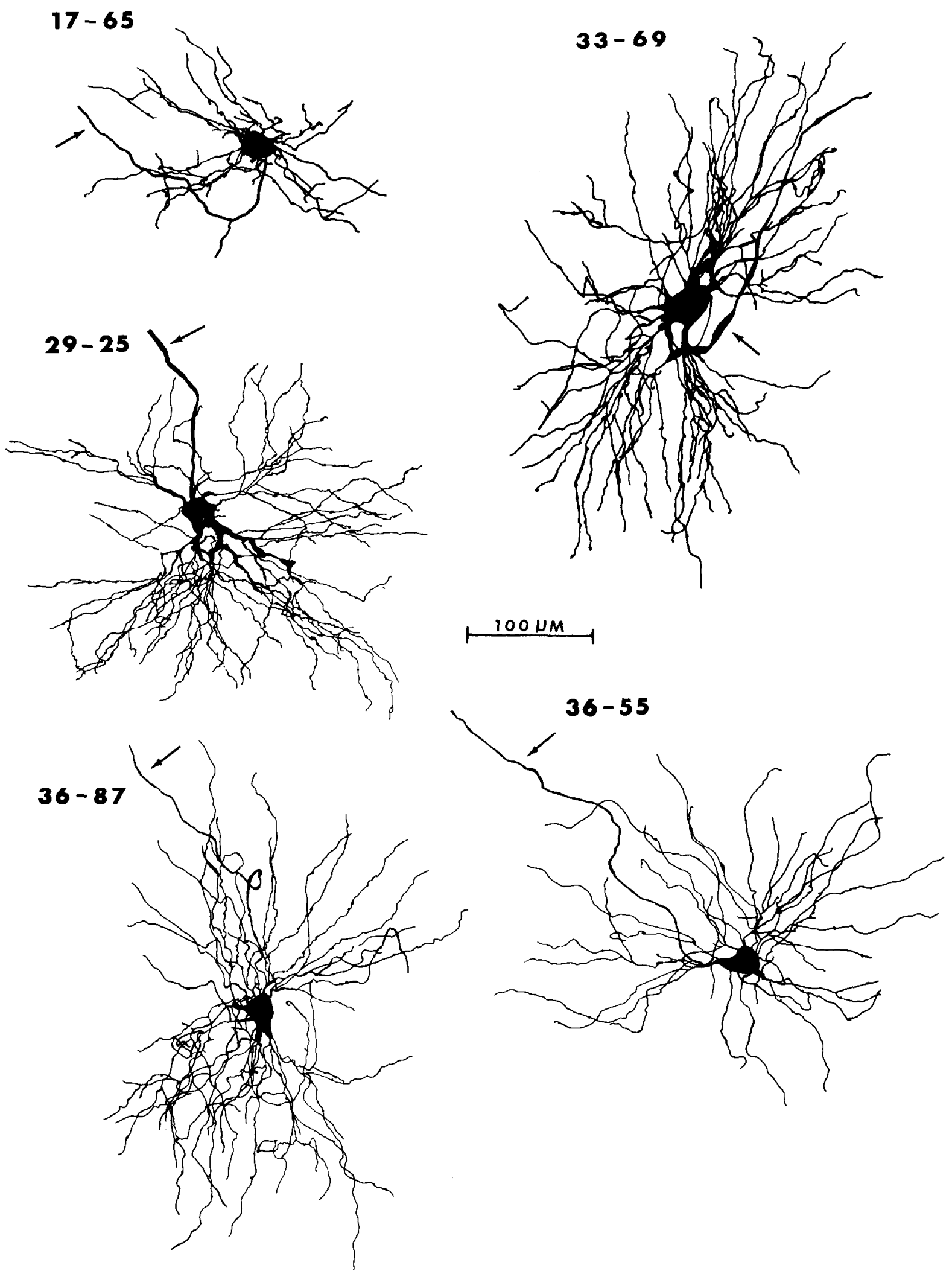

Figure 2. Drawings of magnocellular relay neurons that were filled with HRP in the monkey's LGN. Cells 17-65 and 33-69 were analyzed with the clcctron microscope for synaptic inputs. Properties of these neurons are given in Table 2. Cell 33-69 had a non-linear response (doubling) to a counterphase modulated grating pattern, whereas the rest of the cells had linear response properties (fundamental response and a null position). Arrows indicate the axon for each neuron. 


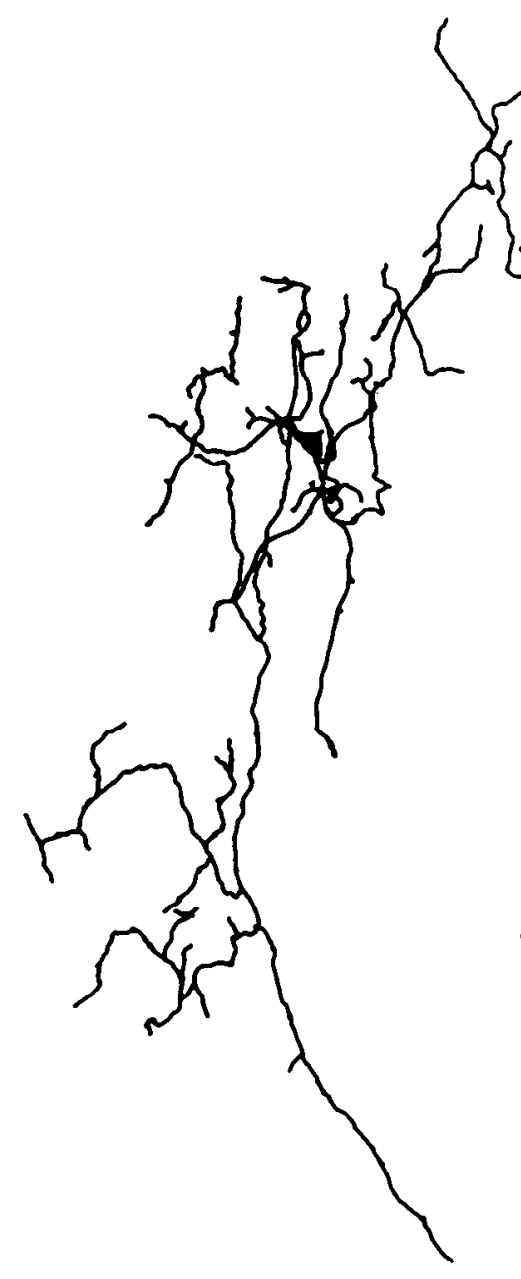

$12-28$

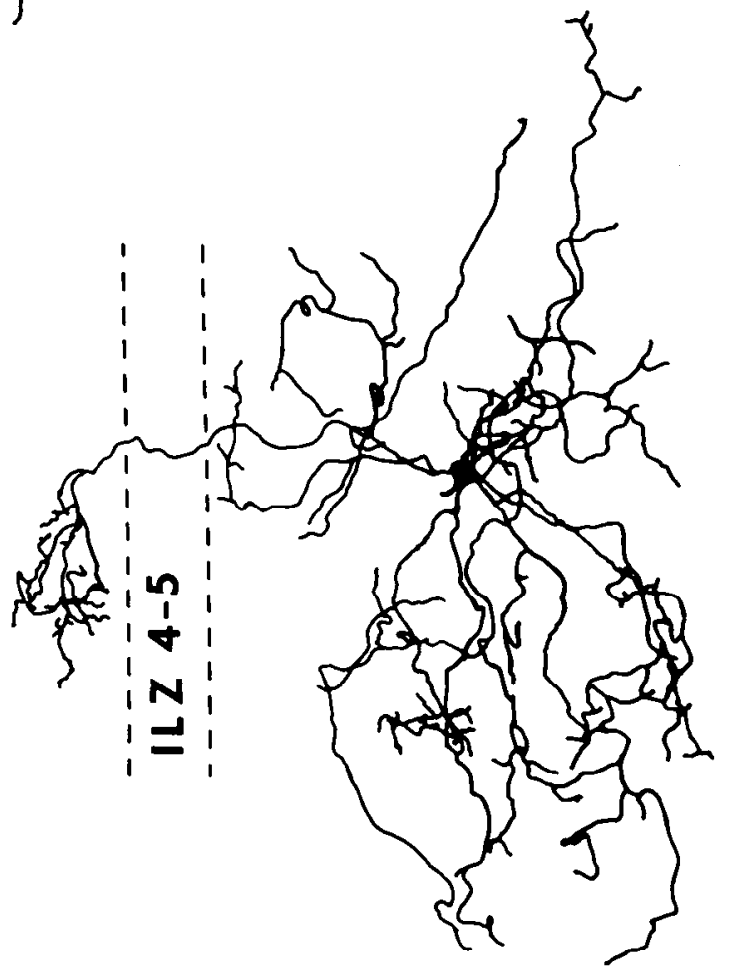

$36-93$
Figure 3. Drawings of 2 interneurons filled with HRP in the monkey's LGN. Properties of these neurons are given in Table 2. ILZ 4-5 indicates the interlaminar zone between laminae 4 and 5 . Note that one of the presynaptic dendrites crosses this zone into lamina 4. It was considered a dendrite because it rcccived synaptic contacts on its proximal part in lamina 5 . sections are easily discernible with the electron microscope. Unstained thin sections allow even the smallest structures containing HRP to be readily found and related to adjacent stained sections and light microscopic drawings. The overall density is dependent on the amount of HRP injected, and many intracellular constituents are usually obscured by the reaction product (Figs. 4, 7, 8, 10). HRP-filled somata of relay cells had EM characteristics that were the same as previously described by other researchers (Colonnier and Guillery, 1964; O'Leary et al., 1965; Pecci-Saavedra et al., 1968). Very few synapses were observed onto the somata in this study, but very dense HRP in this region made it difficult to see synaptic thickenings.

Synaptic distributions. The dendrites of HRP-filled relay neurons in the monkey's LGN received synapses from all 3 of the terminal types (RLP, RSD and F). However, the location or distribution along the dendrites varied with each synaptic type (Figs. 5, 6). For parvocellular relay neurons, retinal terminals mostly contacted proximal dendrites $(0-70 \mu \mathrm{m}$ from the soma center), whereas magnocellular neurons had numerous retinal synapses on both proximal and intermediate $(71-140 \mu \mathrm{m})$ dendrites. Protuberances, bumps, or knobs along the relay cell dendrites were always the site of an RLP contact, but the reverse was not always the case; i.e., RLP terminal contacts were not restricted to the knobs. F synapses were mostly located close to the retinal synapses, but additional F synapses were often found on intermediate dendrites and infrequently on distal dendrites. When the F terminals contacting the HRP-filled dendrites could be subclassified, most were of the F2 type for both parvo- and magnocellular neurons.

The distribution of RSD terminals along the dendrites was just the reverse of that observed for retinal terminals; i.c., RSD terminals rarely contacted proximal dendrites but were the main terminal type found on the distal dendrites. Overall, the pattern of synaptic distribution on each dendrite of a relay cell was retinal and $F$ terminals making synapses on the proximal parts and declining with distance from the soma. RSD terminals began contacting the dendrites beyond the retinal terminals usually and became the most prominent type thereafter (Fig. 5).

Triads and other serial synaptic arrangements. The magnocellular relay neurons had more complex synaptic circuitry associated with them compared with the rather simple circuitry associated with the parvocellular relay neurons. That is, the parvocellular neurons received contacts from the 3 terminal types with little contact between types. On the other hand, several types of interconnections occurred between terminals prior to making synapses onto magnocellular neurons. One such ar- 

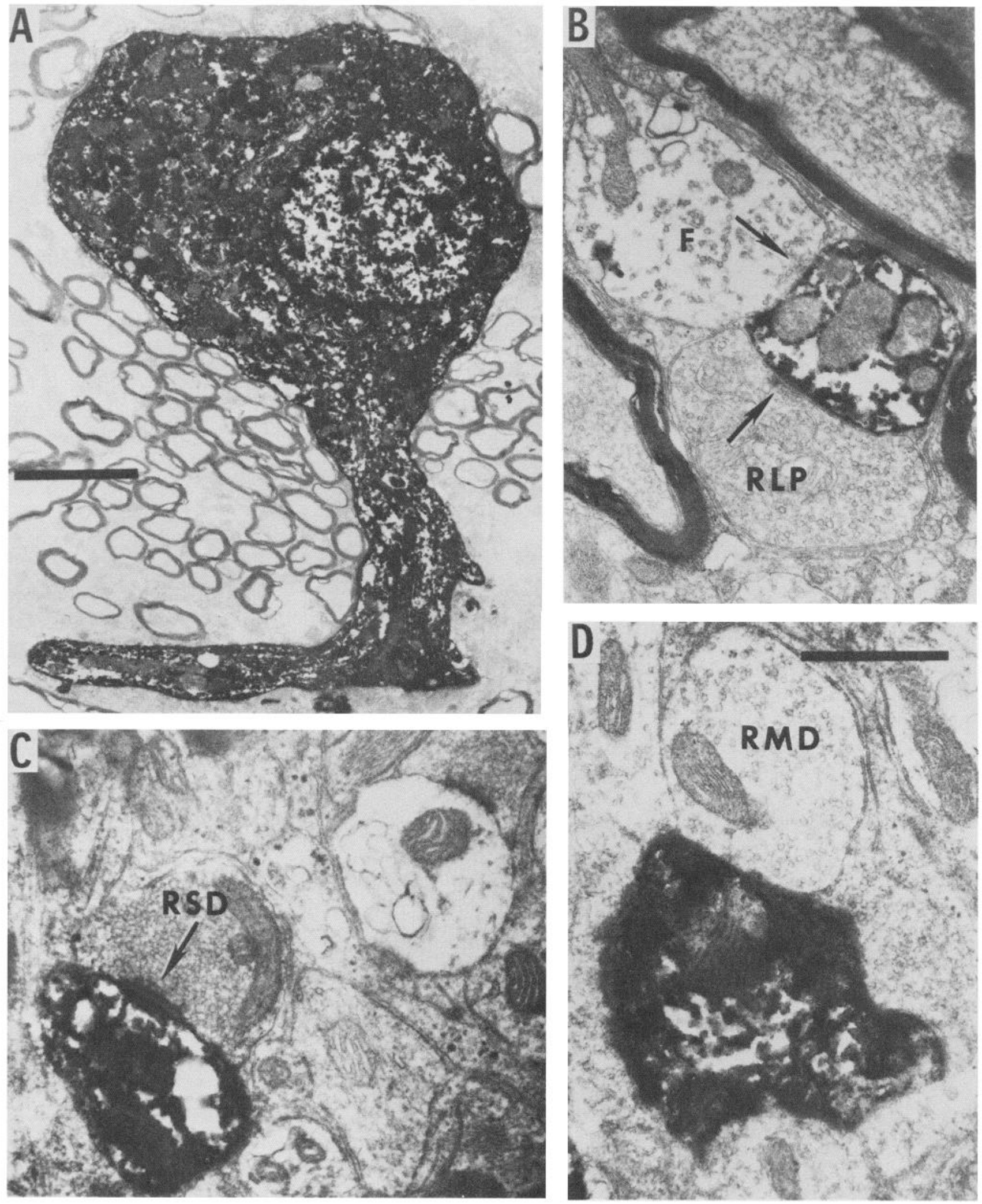

Figure 4. Electron photomicrographs of HRP-filled structures located in the monkey's LGN. $A$, Soma of cell 21-54 showing the nucleus and one proximal dendrite. Scale bar, $6 \mu \mathrm{m}$. B, RLP (retinal) and F (presumed local circuit, GABAergic) terminals contacting an HRP-filled relay cell dendrite at arrows. $C$, RSD (cortical or brain-stem) terminal contacting another HRP-filled relay cell dendrite. $D$, RMD terminal (presumptive brain-stem origin) next to an HRP-filled relay dendrite. Scale bar, $1 \mu \mathrm{m}$, also applicable to $B$ and $C$. 
Table 3. Summary of quantitative data for synapses and dendritic trees of EM examined HRP-filled neurons in monkey's dLGN

A. Synapses counted

\begin{tabular}{|c|c|c|c|c|c|c|c|c|c|c|c|c|c|}
\hline \multirow[b]{2}{*}{ Cell } & \multicolumn{3}{|c|}{$0-70 \mu \mathrm{m}$} & \multicolumn{3}{|c|}{$71-140 \mu \mathrm{m}$} & \multicolumn{3}{|c|}{$>140 \mu \mathrm{m}$} & \multicolumn{3}{|c|}{ Subtotals } & \multirow[b]{2}{*}{ Total } \\
\hline & RLP & $\mathrm{F}$ & RSD & RLP & $F$ & RSD & RLP & $\mathrm{F}$ & RSD & RLP & $\mathrm{F}$ & RSD & \\
\hline $8-28$ & 29 & 23 & 2 & 5 & 6 & 7 & 1 & 0 & 9 & 35 & 29 & 18 & 82 \\
\hline $17-31$ & 15 & 11 & 10 & 0 & 1 & 5 & 0 & 0 & 0 & 15 & 12 & 15 & 42 \\
\hline $21-54$ & 104 & 49 & 4 & 0 & 9 & 45 & 0 & 2 & 11 & 104 & 60 & 60 & 224 \\
\hline $21-66$ & 43 & 32 & 9 & 0 & 2 & 5 & 0 & 2 & 7 & 43 & 36 & 21 & 100 \\
\hline $23-53$ & 106 & 77 & 2 & 2 & 7 & 16 & 0 & 0 & 0 & 108 & 84 & 18 & 210 \\
\hline $17-65$ & 138 & 108 & 16 & 35 & 30 & 56 & 0 & 0 & 13 & 173 & 138 & 85 & 396 \\
\hline $33-69$ & 72 & 61 & 14 & 41 & 52 & 52 & 4 & 10 & 60 & 117 & 123 & 126 & 366 \\
\hline
\end{tabular}

B. Dendritic lengths $(\mu \mathrm{m})$

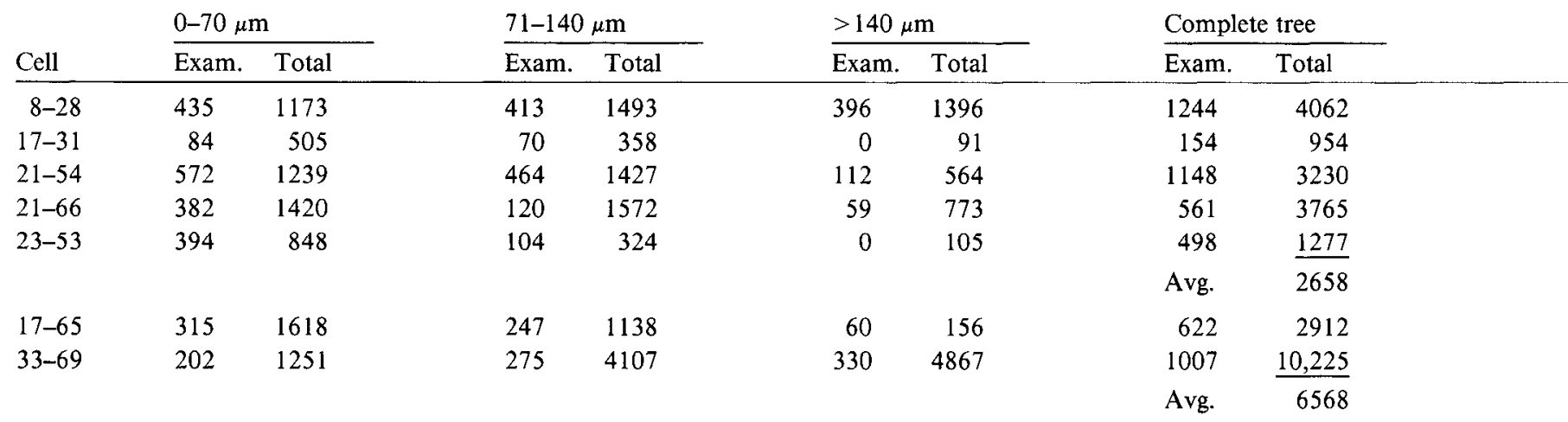

C. Estimated total synapses

\begin{tabular}{|c|c|c|c|c|c|c|c|c|c|c|c|c|c|}
\hline \multirow[b]{2}{*}{ Cell } & \multicolumn{3}{|c|}{$0-70 \mu \mathrm{m}$} & \multicolumn{3}{|c|}{$71-140 \mu \mathrm{m}$} & \multicolumn{3}{|c|}{$>140 \mu \mathrm{m}^{a}$} & \multicolumn{3}{|c|}{ Subtotals } & \multirow[b]{2}{*}{ Total ${ }^{b}$} \\
\hline & RLP & $F$ & RSD & RLP & $F$ & RSD & RLP & $F$ & RSD & $\overline{R L P}$ & $F$ & RSD & \\
\hline $8-28$ & 79 & 78 & 6 & 18 & 27 & 25 & 4 & 0 & 32 & 100 & 105 & 63 & 300 \\
\hline $17-31$ & 90 & 83 & 60 & 0 & 6 & 26 & 0 & 2 & 7 & 90 & 91 & 93 & 300 \\
\hline $21-54$ & 225 & 133 & 9 & 0 & 35 & 138 & 0 & 13 & 55 & 225 & 181 & 202 & 600 \\
\hline $21-66$ & 155 & 144 & 32 & 0 & 33 & 65 & 0 & 33 & 92 & 155 & 213 & 191 & 600 \\
\hline \multirow[t]{2}{*}{$23-53$} & 228 & 206 & 4 & 6 & 27 & 49 & 0 & 8 & 16 & 234 & 231 & 69 & $\underline{500}$ \\
\hline & & & & & & & & & & & & Avg. & 500 \\
\hline $17-65$ & 709 & 693 & 82 & 161 & 173 & 258 & 0 & 0 & 34 & 870 & 866 & 374 & 2000 \\
\hline \multirow[t]{2}{*}{$33-69$} & 446 & 472 & 87 & 612 & 971 & 777 & 37 & 115 & 551 & 1095 & 1558 & 1415 & 4000 \\
\hline & & & & & & & & & & & & Avg. & 3000 \\
\hline
\end{tabular}

"Synapses counted" are an estimate of all synapses on the dendritic tree as derived under the section entitled Total synapses.

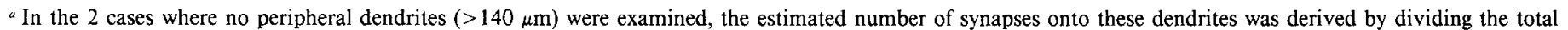

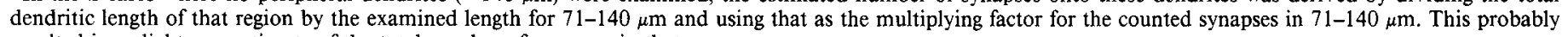
resulted in a slight overestimate of the total number of synapses in that area.

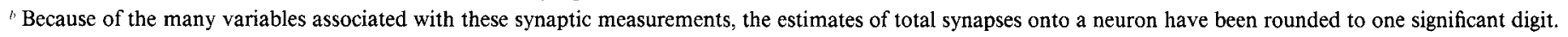

rangement involved a triple synapse in which a retinal terminal contacted both an HRP-filled dendrite and an F2 terminal and the F2 terminal then contacted the same HRP-filled dendrite (Figs. 7, 8). This type of synaptic combination is called a triadic arrangement, triad, or triplet and was most frequently observed in the magnocellular laminae (see also Pasik et al., 1973b; Winfield, 1980; Rapisardi, 1981). Triad will be the term used in this report. Many triads were observed on both magnocellular neurons, so they were not restricted to the linear or nonlinearly responding physiological cell types. Triad number was not quantified because complete serial examination of all scctions was not attempted. Although the number of triads was not quantified, most of the retinal terminals contacting both magnocellular neurons also were observed to contact $F$ terminals. The same F terminals were frequently observed to contact HRP-filled den- drites in other sections. On the other hand, the retinal terminals contacting the HRP-filled dendrites of parvocellular neurons infrequently were observed to be contacting $F$ terminals. In addition to triads, serial synapses between $F$ terminals were sometimes observed in single thin sections prior to their contacting the HRP-filled dendrites of magnocellular neurons. In many of these cases, an F1 type terminal contacted an F2 terminal, which then contacted the HRP-filled dendrite (Fig. $7 D$ ). F1 type terminals also contacted dendrites of presumptive relay cells without an F2 terminal interposed. Another common serial synaptic arrangement involved triads with an F1 contacting the F2 terminal of a triad. While triads and serial synaptic arrangements were observed onto the dendrites of parvocellular neurons, they were rare.

Total synapses. Dendritic trees were arbitrarily divided into 


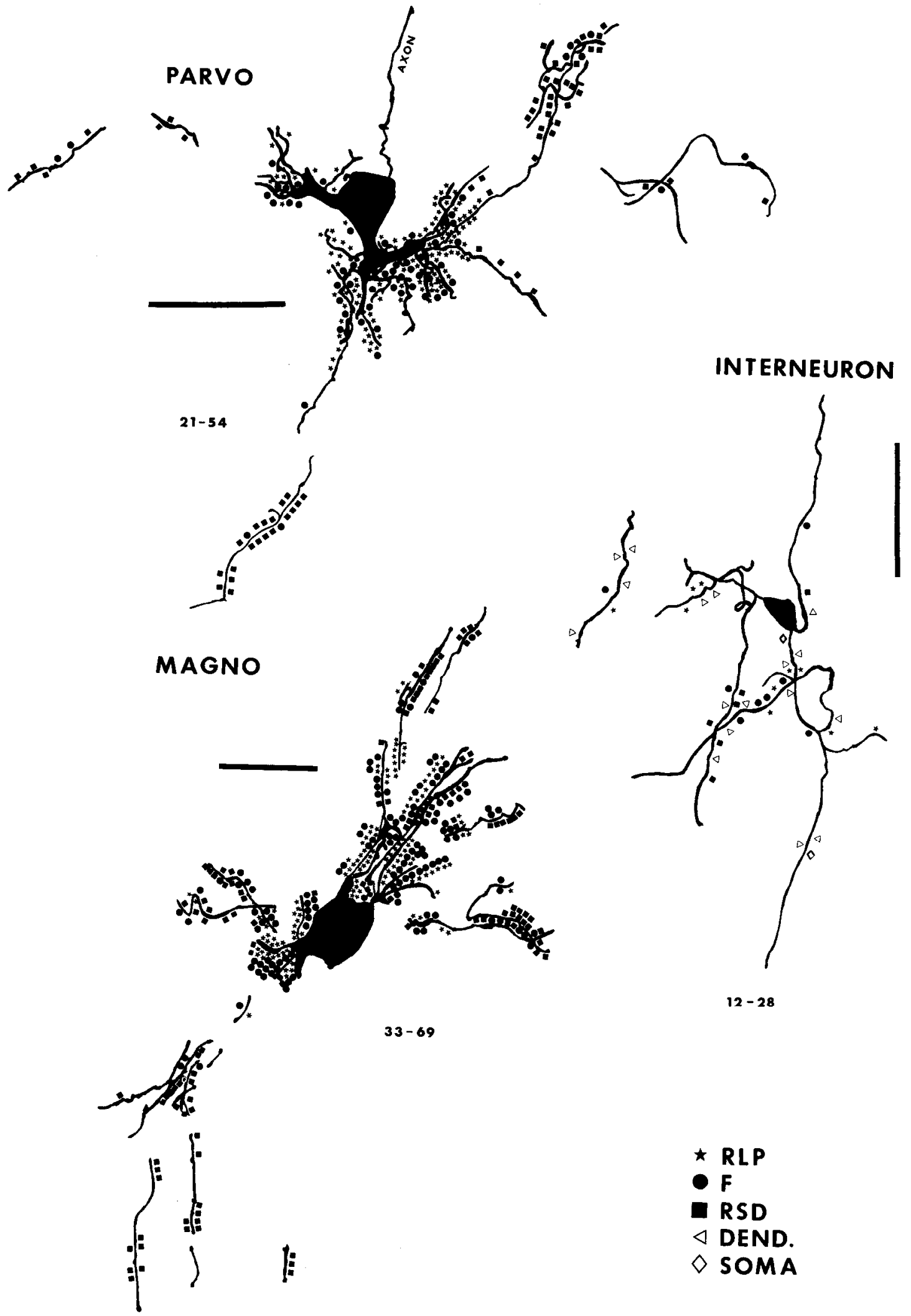

Figure 5. Drawings of the dendrites and somata of 3 representative HRP-injected neurons showing the positions and types of terminals contacting the dendrites. The drawings for the magnocellular and parvocellular neurons represent the HRP-filled structures that were cut and examined with

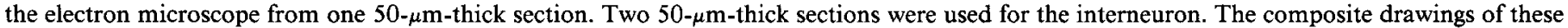
neurons, as numbered, are shown in Figures 1-3. RLP, F, and RSD symbols represent a synapse of that terminal type contacting the HRP-filled dendrite, whereas the dendritic ( $D E N D$ ) and soma symbols represent synapses by presynaptic dendrites of the interneuron onto those structures. The small asterisk represents an RMD type terminal contacting the magnocellular neuron. Scale bars, $50 \mu \mathrm{m}$. 
3 regions: proximal $(0-70 \mu \mathrm{m}$ from the center of the soma), intermediate $(71-140 \mu \mathrm{m})$, and distal $(>140 \mu \mathrm{m})$. Estimates were made of the total number of synapses contacting the proximal, intermediate, and distal dendritic regions (Fig. 6C). An estimate was also made of the number of synapses contacting the entire dendritic tree of each neuron. To derive these estimates, measurements were made from 2-dimensional drawings of the total lengths of all of the dendrites in each region for an individual neuron and also the lengths of the dendrites which were cut and examined for synapses. The ratio of these 2 lengths (total and examined) for each neuron in each region provided a multiplication factor to derive the total estimated synaptic number from the actually counted number of synapses for each region (Table 3 ). An additional factor considered was the number of synapses missed because of examination of only every 4 th thin section. This factor was significant only for $F$ synapses because they tended to be more difficult to observe than the retinal or RSD synapses; i.e., their postsynaptic densities were not prominent. In a count of every section in a series along a few dendrites, $44 \mathrm{~F}$ terminals were observed compared with only 35 observed using every 4 th section of the same series. Therefore, a correction factor of 1.25 was used to multiply the actual synaptic count of $F$ terminals in order to derive their estimated total number. All synapses of the RLP and RSD terminals were observed using every 4 th section and were not recounted if observed again in a nearby section, so no correction factor was necessary for these types of synapses. An additional correction was made for the length of the dendrites in the 3-dimensional compared with the 2-dimensional drawings. The correction used was the value of the sine of $45^{\circ}$ because this angle would be the average direction of a dendrite from a neuron with dendrites extending in all directions, and the sine of $45^{\circ}$ would be the horizontal or drawn length. Thus, all dendritic length values were divided by 0.7071 .

From Table 3, the average parvocellular relay neuron received a total of about 500 synapses on its dendritic tree with most contacting the proximal and intermediate dendrites. The 2 magnocellular neurons had about 2100 and 4100 synapses per neuron (average, 3000). However, as judged from Figure 2, neuron 33-69 is probably more representative of a magnocellular cell than neuron 17-65.

Synapses per unit dendritic length. Besides the types of synapses, their distributions, and overall number, the number of synapses per unit dendritic length is likely to be an important parameter for determining the synaptic effect on the postsynaptic cell. This is particularly true for terminals originating from a single axonal arborization because of the nearly simultaneous arrival of action potentials at all of its terminals. Synaptic density (synapses per unit membrane area) might be even more important, but this requires an accurate measurement of the dendritic diameters, which was not attempted in this study. The synapses per dendritic length are easily calculated from the dendritic lengths in each region of each neuron and the number of synapses estimated. Figure 9 shows these values for each terminal type in each region of the dendritic tree.

For the proximal dendrites, there was an average of about 0.3 synapses (all types) per micron of dendritic length for parvocellular neurons and about 1.0 synapse per micron for magnocellular neurons. These values declined by an average of about $50 \%$ for the intermediate dendrites and continued to decline to
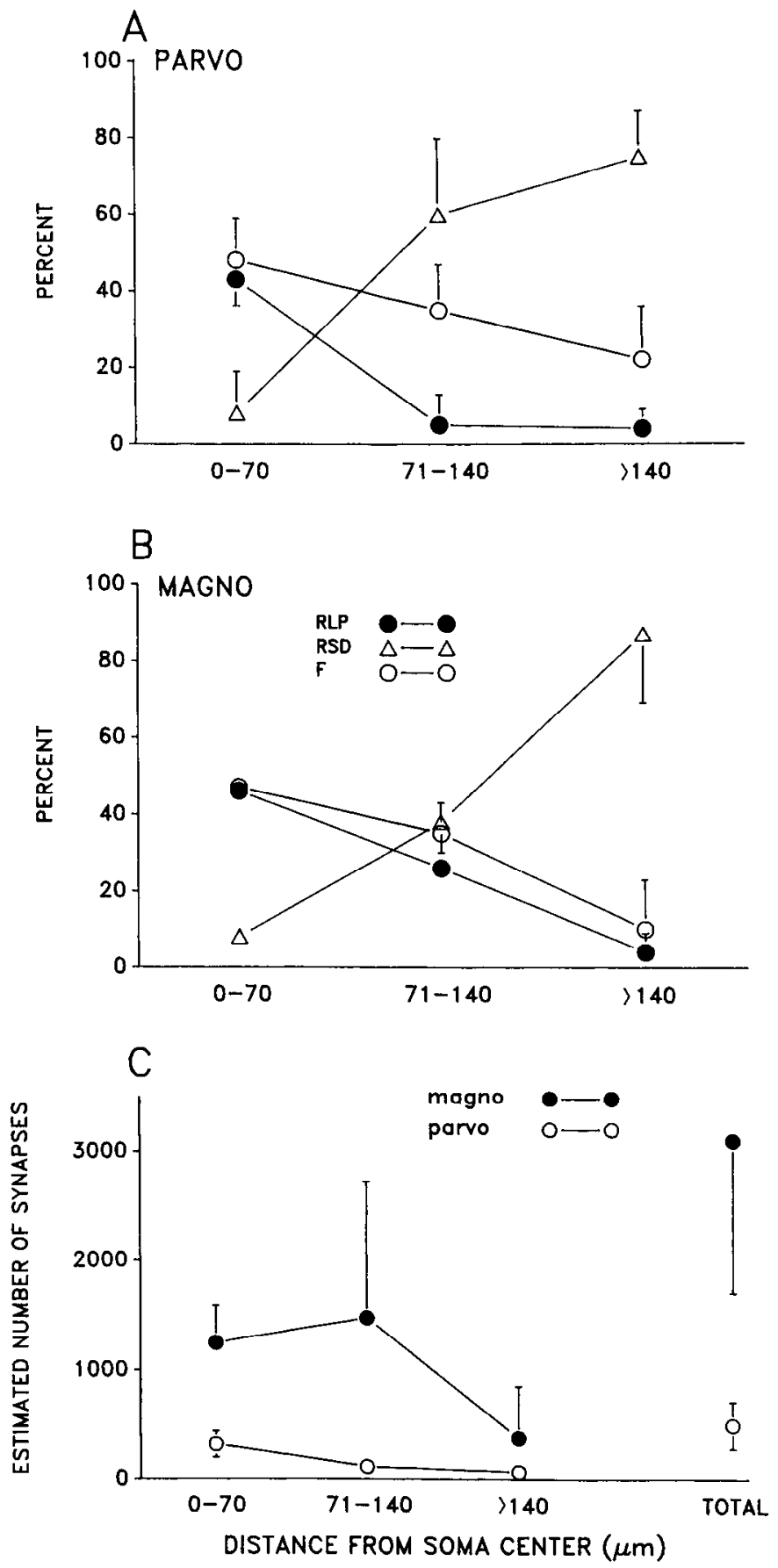

Figure 6. $A$ and $B$, Graphs of the percentage of terminal types making synapses onto dendrites at proximal $(0-70 \mu \mathrm{m})$, intermediate $(71-140$ $\mu \mathrm{m})$, and distal $(>140 \mu \mathrm{m})$ distances along the dendrites of HRP-filled LGN neurons. The upper $P A R V O$ graph shows the average values and SD bars (not shown when smaller than the symbol) for the 5 parvocellular relay neurons drawn in Figure 1. Similarly, the lower $M A G N O$ graph is data from the $2 \mathrm{EM}$-analyzed magnocellular neurons drawn in Figure 2. The data points are the percentage of terminals of that type for that area of the dendrites (proximal, intermediate, or distal). For example, an average of $48 \%$ of all terminals contacting the proximal dendrites of the parvocellular neurons were $F$ type terminals. C, Graph showing the average total number of synapses estimated to contact a parvo- or magnocellular LGN neuron for each segment along the dendrites. The averages and total are derived from Table 3. 

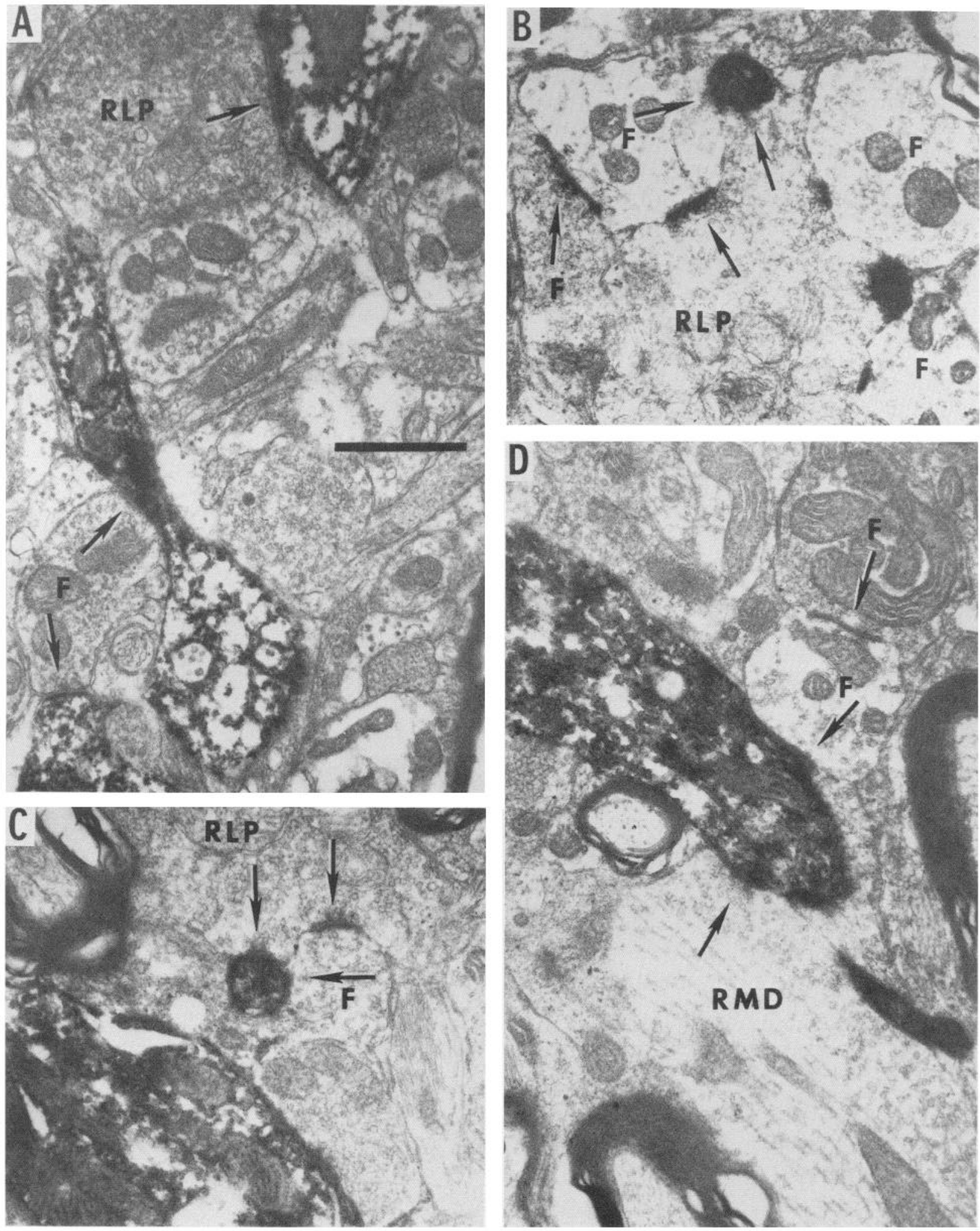

Figure 7. Electron photomicrographs of HRP-filled dendrites from LGN relay neurons, $A, \mathrm{RLP}$ and $\mathrm{F}$ terminals contacting the HRP-filled dendrites of a parvocellular relay neuron at arrows. $B$, Triadic synaptic arrangement where an RLP terminal contacts an F and an HRP-filled dendrite of a magnocellular neuron. The $F$ terminal also contacts the same dendrite. Also note the serial synaptic arrangement in which an $F$ terminal (F1 type) is contacting the $\mathrm{F} 2$ type terminal of the triad. $C$, A triad onto a dendritic knob of a magnocellular relay neuron. All 3 synapses are rarely present in a single section, and the $\mathrm{F}$ contact onto the knob is not very prominent in this section. $D$, A serial synaptic arrangement with an $\mathrm{F} 1$ type terminal contacting an F2 type terminal that is contacting an HRP-filled dendrite of a magnocellular relay neuron. An RMD type terminal is also contacting the same dendrite. Scale bar, $1 \mu \mathrm{m}$. 

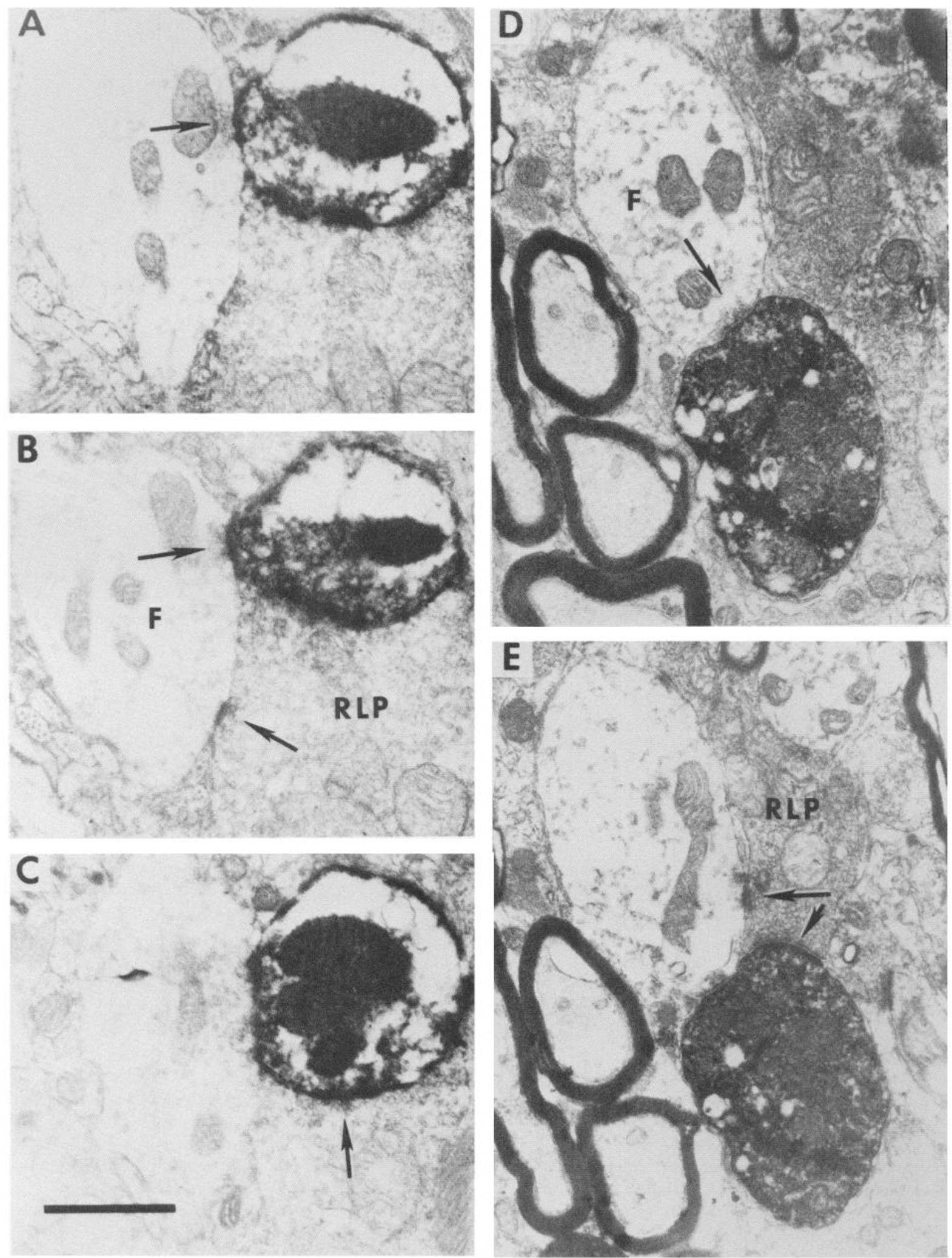

Figure 8. Electron photomicrographs of triads formed from retinal, F2 and HRP-labeled dendrites of magnocellular neurons $(A-C$ are from neuron 33-69; $D$ and $E$ are from neuron 17-65). The figures at left have been printed with a short exposure to allow the darkly stained synapses to be more clearly observed. Arrows indicate synaptic contacts. Scale bar, $1 \mu \mathrm{m}$, in $C$ applies to all photographs. 


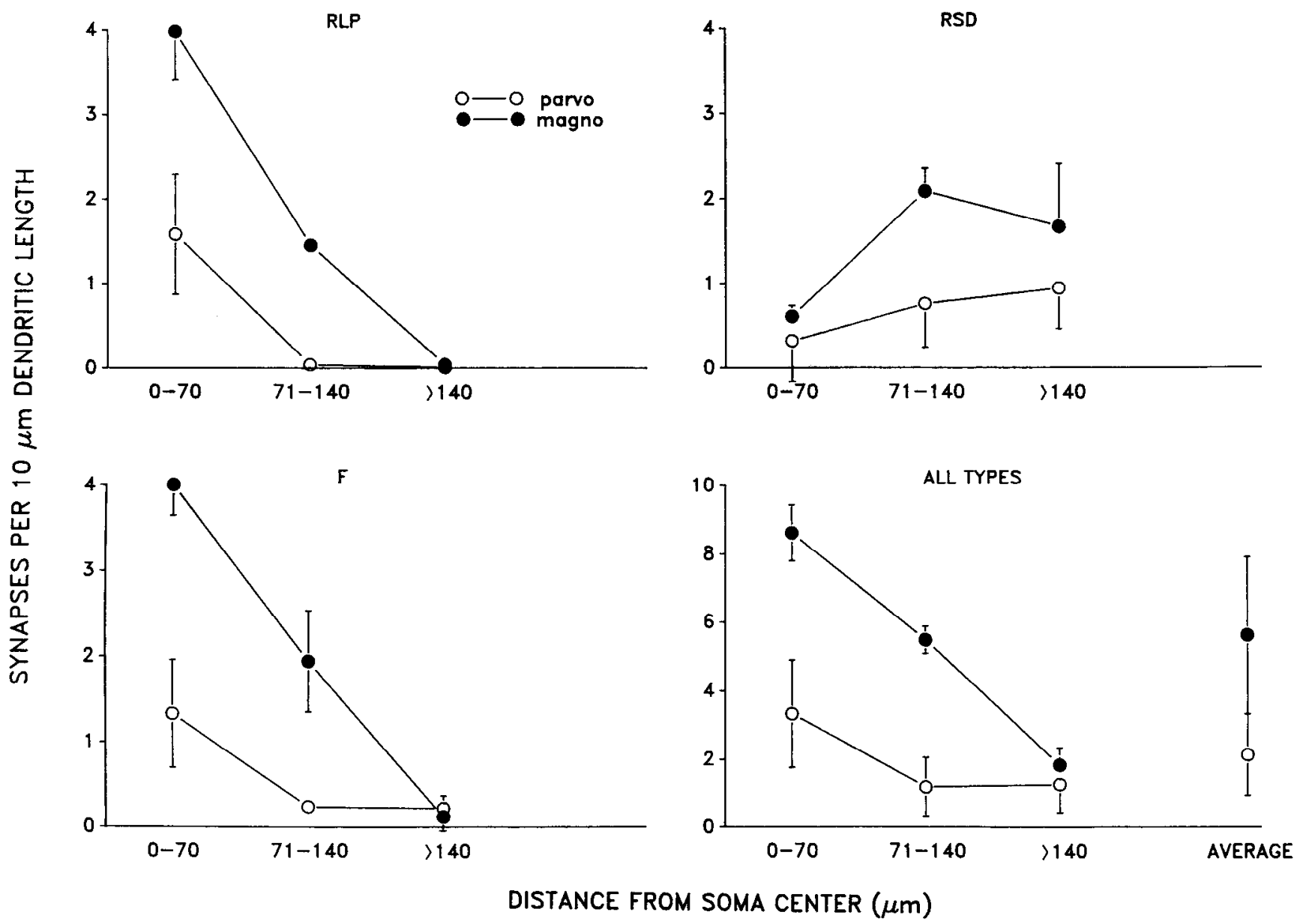

Figure 9. Graphs of synapses per $10 \mu \mathrm{m}$ of dendritic length for parvocellular (average of 5) and magnocellular (average of 2) relay neurons of the LGN as broken down into retinal (RLP), cortical or brain-stem (RSD), and GABAergic (F) terminals. SD bars are not shown when the values are smaller than the symbol.

a low of 0.1 synapses per micron of dendritic length in the distal dendritic regions. The average number of synapses per micron of dendritic length over an entire dendritic tree was about 0.2 for a parvocellular neuron and about 0.5 for a magnocellular neuron.

\section{Interneurons}

Two of the recovered HRP-filled neurons had very small somata and dendritic patterns that were different compared to those of relay neurons (Fig. 3). The soma of one of these neurons was located in lamina 5 , and the other soma was located in the most dorsal lamina of the 4-layered part of the LGN. Most of their physiological properties were similar to those of other parvocellular neurons. The exception to this was that they had off center responses in contrast to the mostly on centers of the relay cells in these laminae (see Table 1; Schiller and Malpeli, 1978). To clarify this last statement in regard to cell $12-28$, the uppermost lamina in the more anterior portion of the LGN is a continuation of laminae 4 and 6 from the 6-layered part of the LGN. Therefore, the receptive fields of the neurons in its lower part are probably ofF center, while those in the upper part are probably on center. The soma of cell 12-28 was located in the upper part of the lamina (see fig. 1 of Wilson, 1986), so it is listed as being in lamina 6 for Table 1. Nevertheless, many of its dendrites extended into the lower half of the lamina, which can be considered as an extension of lamina 4 .

The dendritic patterns of the 2 interneurons were not like relay neurons in that the branches frequently came off at nearly right angles, and the primary dendrites extended for about 300 $400 \mu \mathrm{m}$ from the soma with a maximum of about $600 \mu \mathrm{m}$ observed for one dendrite. Small beads appeared at irregular intervals along both the main dendrites and their branches. IIowever, beads could not be used as a primary characteristic because a few relay neurons also exhibited beads on their dendrites (Fig. 1, cell 8-28, for example).

Much of the dendritic tree of the neuron in lamina 6 (cell 1228) was not observed in the initial search of the wet-mounted tissue, and, thus, the more peripheral dendrites were not embedded in plastic and were unavailable for electron microscopy. The tissue fixation for the second neuron (cell 36-93) was rather poor, so the EM work done on it was limited. Therefore, the EM data from these 2 neurons were useful and important but limited to qualitative observations.

The somata of the interneurons, when examined with EM, showed large nuclei with sparse cytoplasm (Fig. 10, $A, B$ ). The density of the HRP obscured much of the detailed morphology, but one nucleus clearly had deep invaginations of the nuclear envelope (cell 12-28). 

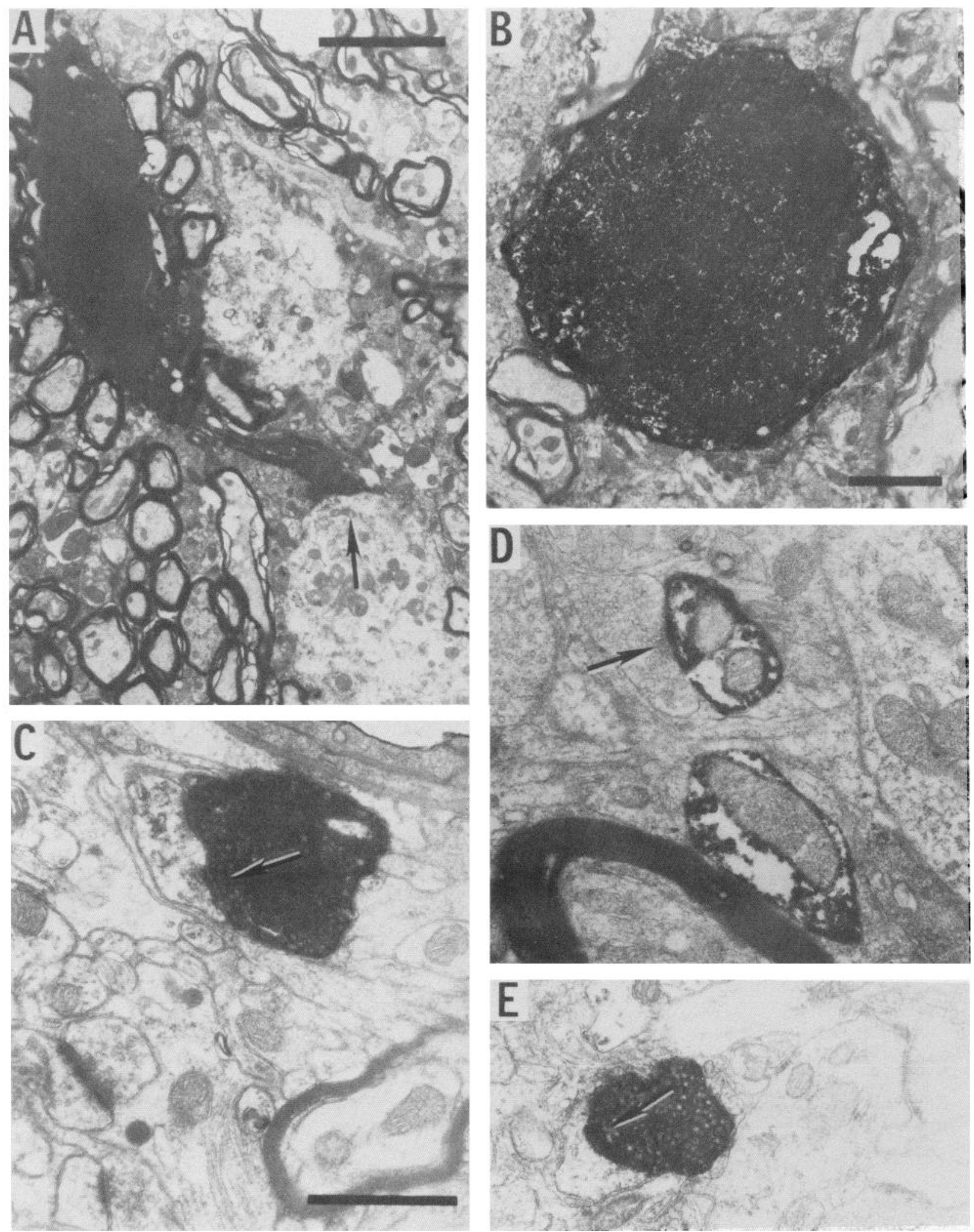

Figure 10. Electron photomicrographs of interneurons. $A$ and $B$, HRP-filled somata of the 2 interneurons drawn in Figure 3 . Arrow in $A$ indicates where a presynaptic dendrite contacts (not visible at this magnification) a large proximal dendrite presumed to be from a relay neuron. Scale bars: $A, 5 \mu \mathrm{m} ; B, 2 \mu \mathrm{m}$. C, An HRP-filled presynaptic dendrite from an interneuron contacts a presumptive relay cell dendrite at the arrow. Synaptic vesicles are outlined by HRP in the presynaptic dendrite. $D$, An RSD terminal contacts an HRP-filled dendrite of an interneuron. $E$, Another vesicle- and HRP-filled presynaptic dendrite with a synapse onto a presumptive relay cell dendrite. Scale bar $(C-E), 1 \mu \mathrm{m}$. 
Both interneurons had synaptic vesicles located in all of the processes examined using the electron microscope (Fig. 10, C, $E)$. Synaptic densities were observed on the membranes next to the synaptic vesicles. These synapses contacted dendrites that were presumed to be relay cell dendrites. The HRP-filled dendrites also received contacts from RLP, RSD, and F terminals. One of these presynaptic dendrites received synaptic contacts from retinal terminals that also contacted the same relay cell dendrites as the presynaptic dendrites (i.e., formed a triad). Because the processes from these neurons received contacts as well as making contacts, they were considered to be presynaptic dendrites. When an HRP-filled presynaptic dendrite containing synaptic vesicles contacted a terminal that also contained pleomorphic synaptic vesicles, the direction of the synapse could not be determined. Despite the extended observations made on the dendrites of these 2 neurons (several 50- $\mu$ m-thick sections were examined), the synaptic contacts made onto them were infrequent compared with relay cells (Fig. 4: compare the parvoand magnocellular neurons versus the interneuron).

Most of the dendrites of cell 36-93 were located in lamina 5 along with the soma (Fig. 3). One presynaptic dendrite, which also received synaptic contacts, crossed laminar boundaries and ended in a complex branching pattern in lamina 4 with presynaptic contacts onto dendrites. Retinal and $F$ terminals contacted the HRP-filled dendrites both in lamina 5 and in lamina 4 . No response to visual stimuli through the nondominant eye was heard, but only a superficial check was made during the recordings.

There were no processes originating from the somata or dendrites of either interneuron that left the vicinity of the dendritic arbors. No myelinated, HRP-filled process was observed for one of these neurons (Fig. 3, neuron 12-28). An HRP-filled myelinated axon was observed in the dendritic field of the second neuron, but this axon was traced to another HRP-injected neuron a few hundred microns away that had the typical features of a relay cell. The latter neuron was in another lamina and had previously been recorded and injected along the same electrode track.

\section{Discussion}

The main findings of this paper are (1) the types and distributions of synapses on the dendritic trees of all relay LGN neurons are similar: RLP (retinal) inputs are close to the soma, F (GABAergic) terminals are mostly near the retinal inputs, and RSD (cortical and/or brain-stem) terminals are on intermediate and distal dendrites; (2) magnocellular neurons have 2-3 times more synapses per dendritic length and about 6 times the total number of synapses of parvocellular neurons; (3) magnocellular neurons, both linearly and nonlinearly responding types, have complex synaptic inputs. such as triads, whereas parvocellular neurons have relatively few such involvements of their inputs; (4) parvocellular interneurons have electrophysiological properties similar to the relay neurons in their laminae with the exception that at least some of them have center responses that are of the opposite sign of the relay cells around them.

\section{Types and distributions of synapses}

Figure 11 provides an illustration of the results of this study which will be discussed in this section along with some of the other known circuitry for the monkey's LGN. The primary sensory inputs, of course, are the retinal afferents. Retinal terminals contact relay neurons mostly on their proximal dendrites just as they do for cat LGN neurons, and this is not too surprising. In this position, these terminals can strongly influence the initial segment of the LGN neuron. If it is assumed that only one or a few retinal ganglion axons provide the input to relay neurons of the monkey's LGN, as is the case for the cat (Cleland et al., 1971; Hamos et al., 1987; Mastronarde, 1987b), then the synchrony of the terminal depolarizations coupled with their proximity to the LGN neuron's initial segment should provide a very high transfer ratio so that information from the retina can be fully relayed to the cortex under the appropriate conditions such as in the awake, active state.

On the other hand, the position of most of the F terminals, being very close to the retinal terminals, is ideal for lowering the transfer ratio by inhibitory mechanisms. Such inhibition could also affect signals from more distal points on the dendrites where cortical and/or brain-stem afferents (RSD) make their contacts. Lowering the transfer ratio or the signal-to-noise ratio would presumably reduce the information going to the cortex during conditions such as sleep or inattention (e.g., Coenen and Vendrik, 1972; Livingston and Hubel, 1981; Hirsch et al., 1983; McCorley et al., 1983; Holdefer et al., 1989). Because many F terminals onto the HRP-filled dendrites appeared to be F2 type terminals, it is presumed that they were from presynaptic dendrites as illustrated in Figure 11. However, some of them may have been terminals from axons of interneurons as observed in the cat by Montero (1987). Fl type terminals were infrequent, but when identified, they were always presynaptic in any synaptic arrangement. Most of the serial arrangements other than triads had an F1 terminal contacting an F2 terminal, which then contacted a presumptive relay cell dendrite. In the rat, F1 terminals have been shown to be derived from the reticular nucleus of the thalamus (Ohara et al., 1980; Montero and Scott, 1981). Part of the pregeniculate nucleus (PGN) of the monkey is the equivalent of the visual portion of the rat's reticular nucleus of the thalamus (Babb, 1980). If F1 terminals of the monkey are also derived from the pregeniculate, then the serial connections with F2 type terminals suggests that the PGN could not only inhibit LGN relay neurons by direct contact with its dendrites, but also disinhibit them via the synapses onto F2 terminals. Perhaps the distance of the neuron from the retinotopic locus of the visual stimulus determines whether inhibition or disinhibition occurs on the neuron (Schmielau and Singer, 1977; Tsumoto et al., 1978). Since the pregeniculate nucleus also receives afferents from brain-stem sources and collaterals from corticogeniculate axons, it is clearly an important and complex source of modulation for sensory signals passing through the LGN (e.g., Jones, 1975; Babb, 1980; Crick, 1984).

The cortex is a major source of neurons providing axons that end as RSD type terminals (Jones and Powell, 1969; Pasik et al., 1973a; Robson, 1983). Although the present study was unable to determine the source of RSD terminals onto the examined relay neurons and interneurons, it seems probable that a large percentage of the RSD terminals observed onto the HRPfilled neurons of this study were from the cortex. A recent study by Weber and Kalil (1987) in the cat concluded that more than $50 \%$ of all RSD terminals observed in the LGN were derived from the brain stem. The monkey has not been studied in this respect, but within the brain stem, several nuclei contribute afferents to the monkey's LGN that might terminate as RSD or similar type terminals at the EM level. First, the superior colliculus sends axons with RSD and RMD type tcrminals into the areas of the LGN where W-like cells reside (Robson and Hall, 

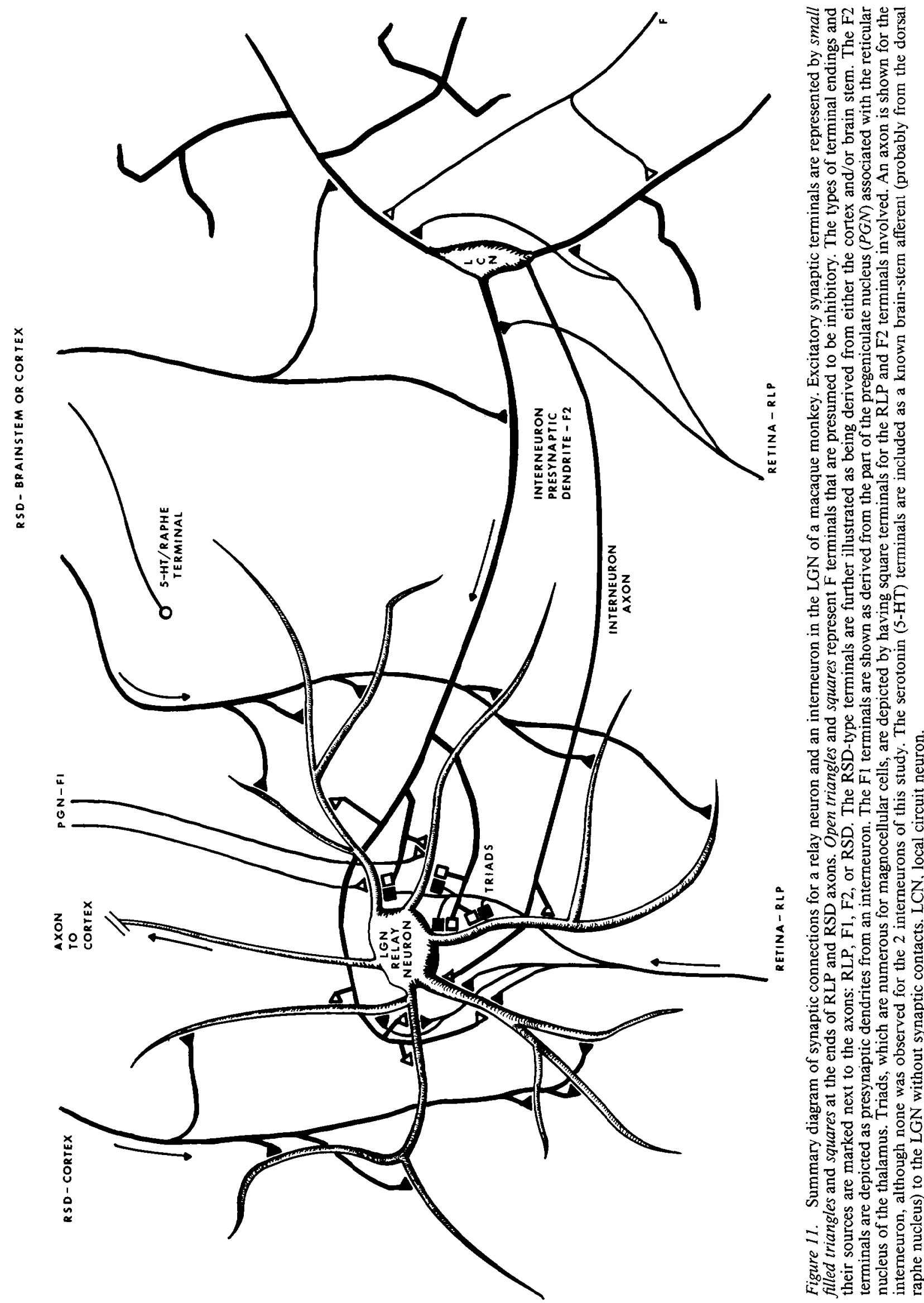
1977; Torrealba et al., 1981). Light microscopic evidence indicates similar projection sites for monkeys (Benevento and Fallon, 1975; Harting et al., 1978). These areas for the monkey are the $\mathrm{S}$ laminae and the interlaminar zones around the magnocellular laminae. The superior colliculus is not likely to be the source of RSD terminals onto the parvocellular HRP-filled neurons, and would probably contribute only a few, at most, RSDs onto some dendrites of magnocellular neurons extending into the interlaminar zones. As a second possible source of brain-stem terminals, deLima et al. (1985) found in the cat that terminals containing $\mathrm{ACh}$ have synapses in the peripheral part of glomerular areas, i.e., close to the retinal terminals. These terminals were not labeled as RSD types in their study but did have some RSD characteristics and would have been counted as RSD types in the present study (see also Cucchiaro et al., 1988). Although the monkey's LGN also has ACh within it (Fitzpatrick and Diamond, 1980; Dean et al., 1982; Graybiel and Ragsdale, 1982; Hess and Rockland, 1983), the EM termination sites are unknown. Occasionally, RSD type terminals were observed near retinal terminals in the present study and their source could have been from brain stem. Finally, serotonin-containing terminals have some of the characteristics of RSD terminals, but they rarely make any synaptic contacts at all (deLima and Singer, 1987; Wilson and Hendrickson, 1988). Therefore, they would not be included in the RSD terminals of this study. Terminals from other brain-stem sources to the LGN such as the pretectal and parabigeminal nuclei (Harting et al., 1986) and locus coeruleus, if they exist (Foote and Morrison, 1987), have not been studied at the EM level.

Terminals of the RSD type were mostly distributed along the intermediate and distal dendrites, which would reduce their effect on the initial segment of a relay cell compared with retinal terminals. However, measurements of the electrotonic length of the dendrites of cat LGN neurons indicate the possibility of only a moderate decrement of about 30-40\% (Bloomfield et al., 1987). If individual RSD terminals are able to generate EPSPs approximately equivalent to individual RLP terminals, then they are still capable of a strong influence on the cell's initial segment because they constitute about one-third of all synaptic input to each neuron. The main requirement for a significant effect might then be the synchronization of their combined firing patterns. As mentioned, the retinal terminals in the cat are able to achieve this by having most of the terminals derived from only one or a few ganglion cell axons, but this is probably not the case for RSD terminals. The monkey has not yet been studied for this point, but 2 studies in the cat have estimated that hundreds of neurons might be required to supply all of the RSD type terminals onto a single LGN neuron (Robson, 1983; Sherman and Koch, 1986). Similar numbers might be expected for monkey magnocellular neurons, but considerably less would be required for parvocellular neurons (see section on Total Synapses). In any case, if single cortical or brain-stem neurons contribute only part of the RSD terminals for a single LGN neuron, then many of these afferents need to be firing synchronously to strongly influence the LGN neuron (see also Wilson et al., 1984).

A further consideration regarding the characteristic distributions of synapses onto the dendrites of LGN neurons is how the distributions were achieved. Do the afferent axon terminals and presynaptic dendrites recognize only selected sites for making synapses (positional markers) or do the distributions derive from physical constraints imposed during development? For example, physical constraints might involve the portion of the dendritic tree available during synaptogenesis. Retinal and cortical axons reach the LGN long before birth in the monkey with retinal axons arriving before cortical axons (Hendrickson and Rakic, 1977; Shatz and Rakic, 1981). During this time, the dendrites of the LGN neurons are presumably growing. It is then possible that the initially short dendrites, destined to become the proximal dendrites, would have mostly retinal terminals available at this point in dendritic development. RSD terminals would arrive later and be available for synapses onto the intermediate and distal dendrites. This developmental sequence, although possible, has little data to support it. Furthermore, the synapses of $F$ terminals appear to develop mostly after birth (Hendrickson and Rakic, 1977). Given their position close to the retinal terminals on proximal dendrites, the F terminal distribution is therefore unlikely to be related to the initial dendritic development. The last point suggests that the distribution of $F$ terminals onto an individual neuron's dendritic tree may be determined by positional markers on the dendrites, and this may also be the case for other terminal types as well.

\section{Interneuron properties}

The small sizes of the somata and the unusual dendritic patterns of the 2 interneurons examined in this study agree with previous reports of these neuronal properties for presumptive interneurons studied with Golgi methods in the monkey (Saini and Garey, 1981; Wilson and Hendrickson, 1981; Conley et al., 1987). The present finding that these interneurons had presynaptic dendrites confirms previous EM studies that have shown synaptic vesicles in neuronal processes also containing ribosomes - a characteristic of dendrites (Guillery, 1969; Wong, 1970; LeVay, 1971; Famiglietti and Peters, 1972; Lieberman and Webster, 1974; Hámori et al., 1975; Pasik et al., 1976). Because immunocytochemical methods at the EM level reveal similar processes and their terminals to contain GABA (Hendrickson et al., 1983), while having no axons projecting to cortex (Montero, 1986b), these interneurons can be physiologically defined as part of the intrinsic, inhibitory circuitry of the LGN. Therefore, interneurons are involved in key inhibitory roles in the functional aspects of processing of visual signals in the LGN (Sillito and Kemp, 1983; Holdefer et al., 1989).

One aspect of these interneurons that does not match previous studies is the lack of an axon for either neuron. Local circuit, myelineated axons have been reported for LGN interneurons of the cat and monkey (Hámori et al., 1978; Hamos et al., 1985). In the present study, no myelineated structures were observed anywhere around one interneuron and the myelineated axon observed in the nearby neuropil of the sccond interneuron appeared to originate from a separately injected relay cell. Additionally, the somata were closely checked for any processes not labeled with HRP projecting from them, but none were found. All of the unmyelineated processes from the somata of the 2 neurons appeared to be dendrites. One of the presynaptic dendrites of the second neuron even extended into the middle of another lamina. These presynaptic dendrites apparently provided all of the necessary synaptic outlets in the local circuits of the LGN for these 2 interneurons. Questions to be answered are whether the axons of other interneurons extend further than the dendrites to permit more long-distance interactions and whether the interneurons or the axons themselves have different functions compared with the interneurons without axons.

An important contribution of this study was that the physiology of these interneurons was essentially the same as that of 
the relay neurons (see also Hamos et al., 1985, for the cat). Thus, despite having few retinal contacts on their proximal dendrites and no axonal initial segments, their responses were indistinguishable from relay cells, at least using the tests of this study. The single exception related to the sign of the receptive field center response. Whereas most of the neurons in laminae 5 and 6 have on receptive field centers, these 2 interneurons both had ofF centers. Therefore, at least some of the interneurons of the parvocellular laminae have receptive field centers opposite those of the relay cells in the same lamina. Because these interneurons are in a position to mediate feed-forward inhibition, one functional role might be to suppress undesirable surround responses from the relay cells located in the same lamina (see also Sillito and Kemp, 1983). That is, if the retinal input to an ofF center relay cell has a strong surround response (at light oN), then the inhibitory neurons, responding at light oN, could inhibit the surround on responses of the relay cell. Thus, only the off center information would be sent to cortex and not the on surround responses. Related to this possibility was the observation that an oN center cell, which was extracellularly recorded simultaneously with the interneuron in lamina 5 , had a receptive field center adjoining the ofF cell's receptive field center; i.e., the interneuron's center was in the surround area of the relay neuron's receptive field. Despite the attractiveness of such a straightforward function in the LGN's circuitry, it must be considered as an oversimplification because physiological studies that eliminate the oN system pathways using D,L-2-amino-4phosphonobutyric acid (APB) show little effect on the responses of ofF center cells (Schiller, 1982; Horton and Sherk, 1984). If the same is true that on center cells are little affected by oFF center interneurons, it leaves the question of the function for these interneurons unanswered and suggests that further tests, including those under different states of the animal, may be necessary to discern an effect of these interneurons on relay cells.

\section{Comparison of cell types}

A substantial difference is clear at the light microscopic level between the dendritic trees of the 2 magnocellular cells of this study. This difference might correlate with their linear/nonlinear properties. However, several other magnocellular neurons with linear responses have been injected and recovered which have large, widespread dendritic trees similar to that of the nonlinearly responding neuron (Fig. 2). Therefore, the apparent dendritic differences in the 2 analyzed neurons at the light microscopic level are unlikely to be related to their linear or nonlinear response characteristics.

From the EM data, the 2 magnocellular neurons, on average, had about 6 times as many synapses as the parvocellular neurons. About half of this number could be accounted for by the greater total length of dendrites for one of the magnocellular cells. The remaining increase was due to a greater density of synapses on the dendritic trees of both magnocellular neurons. All 3 types of terminals had more synapses on these neurons. This greater synaptic density might relate to the greater soma sizes of these neurons (Henneman and Mendell, 1981). That is, with a larger surface area and possibly a lower overall membrane resistance, more synapses might be required to achieve the necessary current density for influencing the neuron's firing activities. This might also be the reason why the small interneurons had so few synapses on their proximal dendrites; i.e., smaller neurons might need less synaptic input to achieve the necessary current density for activation.
A second major difference between the magnocellular neurons compared to the parvocellular neurons was the greater complexity of the related circuitry for the magnocellular neurons. Triads were common for the magnocellular neurons with other serial synaptic arrangements also observed, while such synaptic circuitry was rarely observed for the parvocellular neurons. Because the number of synapses onto magnocellular neurons is about 6 times that of parvocellular neurons, it is possible that these observations simply reflect their relative probability of being observed within single thin sections. However, these observations qualitatively support 2 other studies that have used serial section analyses of proximal dendrites of monkey LGN neurons and reported similar findings (Winfield, 1980; Rapisardi, 1981). From the present study, both linearly and nonlinearly responding magnocellular neurons have a high number of triads associated with their retinal inputs. This complex circuitry involved with magnocellular neurons indicates that signals being sent through them are capable of being modified more than those passing through the parvocellular relay neurons.

\section{Comparisons with cat data}

Figure 12 provides some comparisons of data derived from cat LGN neurons (Wilson et al., 1984) with data from the monkey. Several points are worthy of note.

First, the total dendritic lengths of cat LGN neurons were similar to magnocellular neurons and about double those of parvocellular neurons of the monkey. Also, there was a higher density of synapses on the dendrites for the cat. The total number of synapses onto an LGN neuron of the cat was about 1.7 times more than for a magnocellular neuron in the monkey and about 8 times more than for a parvocellular neuron. It should be noted that the parvocellular interneurons observed in the monkey have dendritic trees that are much less extensive than those observed in the cat (Friedlander et al., 1981; Hamos et al., 1985). However, magnocellular interneurons have yet to be studied in the monkey, and they may be more comparable to interneurons in the cat because of the need to supply the higher number of $F$ terminals observed in the magnocellular laminae.

Second, the overall distributions of synaptic types (RLP, RSD, F) are very similar between these 2 species with RLP and F types being mostly on dendrites close to the soma and RSD terminals located mostly on intermediate and distal dendrites. However, the percentage of each synaptic type was different between the species. In particular, retinal synapses (RLP) are $30-34 \%$ of all synapses in the monkey, but only $8-12 \%$ in the cat. Because of the larger total number of synapses on neurons in the cat compared with those in the monkey, the RLP terminals onto a neuron in the LGN are about equal for a magnocellular neuron of the monkey and an X- or Y-cell of the cat. On the other hand, F terminals onto a neuron in the cat's LGN outnumber those onto a neuron in the monkey's LGN, even though the percentages are about equal. RSD type synapses on a neuron in the cat's LGN have both a higher percentage and number than on neurons in the monkey's LGN.

The physiological significance of these differences between cat and monkey is speculative, at best, particularly because it is not at all clear whether the major physiological emphasis should be on the relative number or the absolute number of terminals on a neuron. Only RSD terminals have higher percentages and total numbers for the cat versus monkey. Perhaps this reflects a greater influence of cortex or brain stem on neurons in the cat's LGN, but there is little physiological data to address this issue. The 

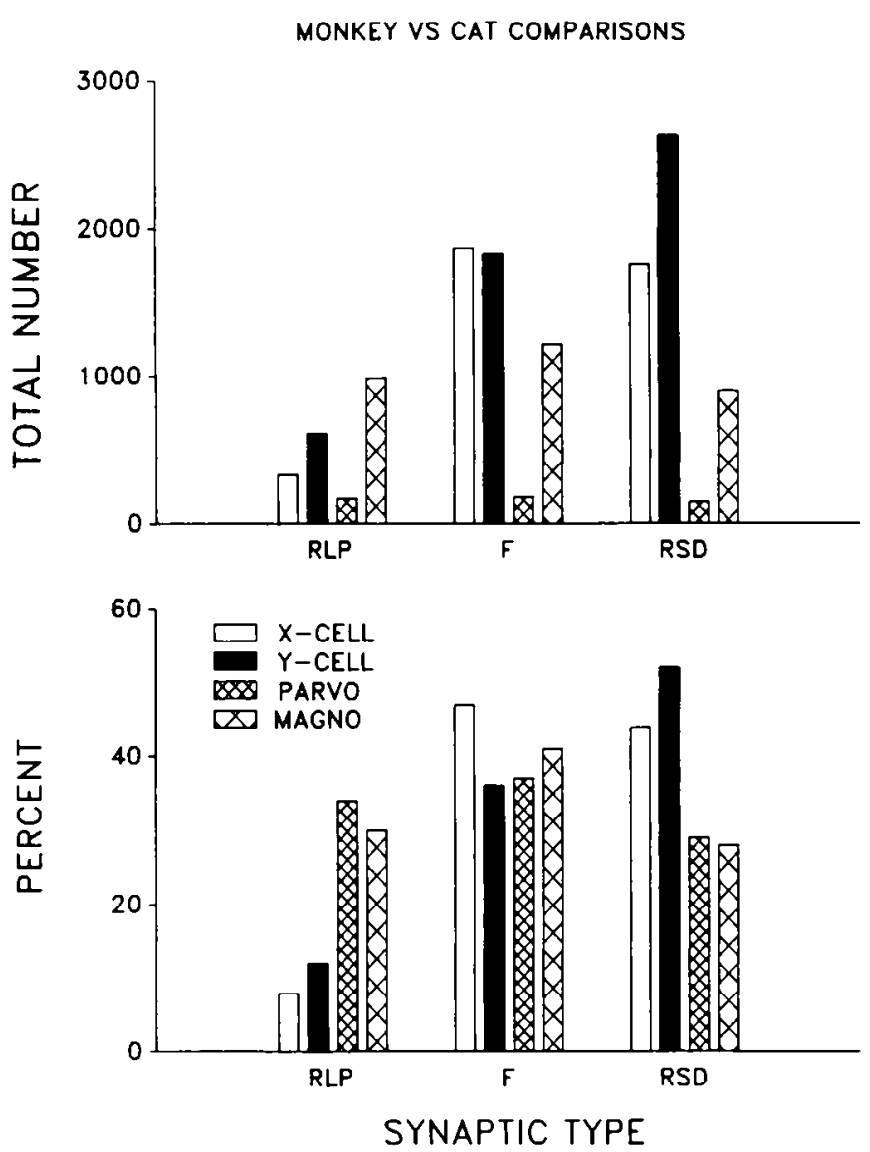

Figure 12. Synaptic comparisons of cat and monkey LGN neurons. The upper graph compares the total number of synapses onto the dendritic trees of X, Y, parvocellular, and magnocellular neurons. Note that the number of synapses onto cat LGN neurons is greater for $F$ and RSD types, but similar for RLP terminals. The lower graph compares the percentages of each terminal type for these same cell types. The percentages are the proportion of each terminal type (RLP, F, RSD) from the total number of synapses onto each type of cell (X, Y, Parvo, or Magno). Note that the percentages for each terminal type contacting monkey LGN neurons are about equal.

only correlation with some data is that of the greater number of $F$ terminals onto LGN neurons of the cat possibly being related to the greater occurrence of nondominant eye inhibition for cat versus monkey LGN neurons (e.g., Sanderson et al., 1971; Marrocco and McClurkin. 1979; Rodieck and Dreher, 1979; see also Wilson, 1982).

In the cat, Class $2 \mathrm{X}$-cells, with many spiny appendages on their dendrites (Guillery, 1966), have a high percentage of triads, whereas Class I Y-cells have few spines and a low percentagc of triads (Wilson et al., 1984). The difference between X-cclls and $Y$-cells was emphasized in that study, but many Class 2 cells are Y-cells (Fricdlander et al., 1981), and many Class 1 cells have recently been observed to be $\mathrm{X}$-cells (Rapisardi et al., 1986; Humphrey and Weller, 1988). Therefore, the more relevant correlation could be that of triads with Class 2 cells as Rapisardi and Miles (1984) have suggested. The appendages or spines of these neurons are unlikely to be a relevant factor because monkey LGN neurons do not usually have such processes on their dendrites yet have many triads for the magnocellular neurons. As a clue to the function of triads, the question could be asked, "What are the common physiological characteristics of Class 2 cells in the cat and magnocellular cells in the monkey which are different from their retinal inputs and might therefore corrclate with triads as the substrate for the differences?" The major problem in attempting to answer this question is the lack of data relating changes in going from retinal signals to LGN signals for both Class 2 cells of the cat and magnocellular cells of the monkey (however, see Shapley et al., 1981; Wilson et al., 1988). For example, magnocellular neurons are phasic relative to the tonically firing parvocellular neurons, but retinal inputs to magnocellular cells are phasic as well (deMonasterio and Gouras, 1975; Schiller and Malpeli, 1977; deMonasterio, 1978; Crook et al., 1988). Whether magnocellular cells are more phasic than their retinal inputs has not been determined. In the cat. $\mathrm{X}$ or sustained cells have lower maintained and driven activities in the LGN compared with their retinal counterparts (Cleland et al., 1971; Bullier and Norton, 1979). If most of the X-cells in these studies were Class 2 cells, then the triads might be the substrate that reduced their activities, although the X-cells clearly have not become phasic in their responses. Stevens and Gerstein (1978) reported an inhibitory pause immediately after a retinal action potential to X-cells in the cat's LGN and suggested that this was due to the triads contacting these neurons. This would have the effect of limiting the rate that these neurons could respond to their retinal inputs or might produce a reduced initial phase as observed for lagged X-cells in the cat (Mastronarde, 1987b; Humphrey and Weller, 1988).

Although their function remains elusive, a clear point in both the cat and monkey LGNs is that triads are the most outstanding synaptic difference between Class 1 and Class 2 cells in the cat and parvocellular and magnocellular cells in the monkey.

\section{References}

Abramov. I. (1968) Further analysis of the responses of LGN cells. J. Opt. Am. 58: 574-579.

Babb, R.S. (1980) The pregeniculate nucleus of the monkey (Macaca mulatta). I. A study at the light microscopic level. J. Comp. Neurol. 190:651-672.

Benevento. L. A., and J. H. Fallon (1975) The ascending projections of the superior colliculus in the rhesus monkey (Macaca mulatta). J. Comp. Neurol. 160: 339-363.

Bishop, P. O.. W. Burke, and R. Davis (1962) The identification of single units in central visual pathways. J. Physiol. (I ond.) 162: 409431 .

Blakemore, C. B., and F. Vital-Durand (1981) Distribution of X-and $Y$-cells in the monkey's lateral geniculate nucleus. J. Physiol. (Lond.) 320: 17-18P.

Blakemore, C. B., and F. Vital-Durand (1986) Organization and postnatal development of the monkey"s lateral geniculate nucleus. J. Physiol. (Lond.) 380: 453-491.

Bloomficld, S. A.. J. E. Hamos, and S. M. Sherman (1987) Passive cable properties and morphological correlates of neurones in the lateral geniculate nucleus of the cat. J. Physiol. (Lond.) 383: 653-692.

Bullier, J., and T. T. Norton (1979) Comparison of receptive field propertics of $\mathrm{X}$ and $\mathrm{Y}$ ganglion cells with $\mathrm{X}$ and $\mathrm{Y}$ lateral geniculate cells in the cat. J. Neurophysiol. 42: 274-291.

Burke, W. and A. M. Cole (1978) Extraretinal influences on the lateral geniculate nucleus. Rev. Physiol. Biochem. Pharmacol. 80: 105-166.

Clark, W. E. (1932) A morphological study of the lateral geniculate body. Br. J. Ophthalmol. 16: 264-284.

Cleland, B. G., M. W. Dubin, and W. R. Levick (1971) Sustained and transient neurones in the cat's retina and lateral geniculate nucleus. J. Physiol. (Lond.) 217: 473-496.

Coenen. A. M. L.. and A. J. H. Vendrik (1972) Determination of the transfer ratio of cat's geniculate neurons through quasi-intracellular recordings and the relation with the level of alertness. Exp. Brain Res. 14:227-242. 
Colonnier, M., and R. W. Guillery (1964) Synaptic organization in the lateral geniculate nucleus of the monkey. Z. Zellforsch. 62: 333355.

Conley, M., F. Birecree, and V. A. Casagrande (1987) Neuronal classes and their relation to functional and laminar organization of the lateral geniculate nucleus: A Golgi study of the prosimian primate, Galago crassicaudatus. J. Comp. Neurol. 242: 561-583.

Crick, F. (1984) Function of the thalamic reticular complex: The searchlight hypothesis. Proc. Natl. Acad. Sci. USA 81: 4586-4590.

Crook, J. M., B. Lange-Malecki, B. B. Lee, and A. Valberg (1988) Visual resolution of macaque retinal ganglion cells. J. Physiol. (Lond.) 396: 205-224.

Cucchiaro, J. B., D. J. Uhlrich, and S. M. Sherman (1988) Parabrachial innervation of the cat's dorsal lateral geniculate nucleus: An electron microscopic study using the tracer Phaseolus vulgaris leucoagglutinin (PHA-L). J. Neurosci. 8: 4576-4588.

Dean, F. F., S. T. Bunch, D. J. Tolhurst, and P. R. Lewis (1982) The distribution of acetylcholincstcrase in the lateral geniculate nucleus of the cat and monkey. Brain Res. 244: 123-134.

deLima, A. D., and W. Singer (1987) The serotoninergic fibers in the dorsal lateral geniculate nucleus of the cat: Distribution and synaptic connections demonstrated with immunocytochemistry. J. Comp. Ncurol. 258: 339-351.

deLima, A. D., V. M. Montero, and W. Singer (1985) The cholinergic innervation of the visual thalamus: An EM immunocytochemical study. Exp. Brain Res. 59: 206-212.

DeMonasterio, F. M. (1978) Properties of concentrically organized X and $Y$ ganglion cells of macaque retina. J. Neurophysiol. 41: 13941417 .

DeMonasterio, F. M., and P. Gouras (1975) Functional properties of ganglion cells of the rhesus monkey retina. J. Physiol. (Lond.) 25l: 167-195.

Derrington. A. M., and P. Lennic (1984) Spatial and temporal contrast sensitivities of neurones in lateral geniculate nucleus of macaque. J. Physiol. (Lond.) 357: 219-240.

DeValois, R. L., I. Abramov, and W. R. Mead (1967) Single cell analysis of wavelength discrimination at the lateral geniculate nucleus in the macaque. J. Neurophysiol. 30:415-433.

Dreher, B., Y. Fukuda, and R. W. Rodieck (1976) Identification. classification and anatomical segregation of cells with $X$-like and $Y$-like properties in the lateral geniculate nucleus of Old World primates. J. Physiol. (Lond.) 258: 433-452.

Famiglietti, E. V., and A. Peters (1972) The synaptic glomerulus and the intrinsic neurons in the dorsal lateral geniculate nucleus of the cat. J. Comp. Neurol. 144: 285-334.

Fit_patrick, D., and I. T. Diamond (1980) Distribution of acetylcholinesterase in the geniculostriate system of Galago senegalensis and Aotus trivirgatus: Evidence for the origin of the reaction product in the lateral geniculate body. J. Comp. Neurol. 194: 703-719.

Fitzpatrick, D., K. Itoh, and I. T. Diamond (1983) The laminar organization of the lateral geniculate body and the striate cortex in the squirrel monkey (Saimiri sciureus). J. Ncurosci. 3: 673-702.

Fonte, S. L., and J. H. Morrison (1987) Extrathalamic modulation of cortical function. Annu. Rev. Neurosci. 10: 67-92.

Friedlander, M. J., C.-S. Lin, L. R. Stanford, and S. M. Sherman (1981) Morphology of functionally identified neurons in lateral geniculate nucleus of the cat. J. Neurophysiol. 46: 80-129.

Gielen, C. C. A., J. A. M. von Gisbergen. and A. J. H. Vendrik (1981) Characterization of spatial and temporal properties of monkey LGN Y-colls. Biol. Cybernet. 40:157-170.

Graybiel, A. M., and C. W. Ragsdale, Jr. (1982) Pseudocholinesterase staining in the primary visual pathway of the macaque monkey. $\mathrm{Na}$ ture 299: 439-442.

Guillery, R. W. (1966) A study of Golgi preparations from the dorsal lateral geniculate nucleus of the adult cat. J. Comp. Neurol. I28: $25-$ 50.

Guillery, R. W. (1969) The organization of synaptic interconnections in the laminae of the dorsal lateral geniculate nucleus of the cat. $Z$. Zellforsch. 96: 1-38.

Guillery, R. W., and M. Colonnier (1970) Synaptic patterns in the dorsal lateral geniculate nucleus of the monkey. Z. Zellforsch. 103: 90-108

Hámori, J., T. Pasik, P. Pasik, and J. Szentágothai (1974) Triadic synaptic arrangements and their possible significance in the latcral geniculate nucleus of the monkey. Brain Res. 80: 379-393.
Hámori, J., P. Pasik, and T. Pasik (1975) Postnatal differentiation of "presynaptic dendrites" in the lateral geniculate nucleus of the rhesus monkey. Adv. Neurol. 12: 149-161.

Hámori, J., T. Pasik, and P. Pasik (1978) Electron-microscopic identification of axonal initial segments belonging to interneurons in the dorsal lateral geniculate nucleus of the monkey. Neuroscience 3:403412.

Hámori, J., P. Pasik, and T. Pasik (1983) Differential frequency of $P$-cells and I-cells in magnocellular and parvocellular laminae of monkey lateral geniculate nucleus. An ultrastructural study. Exp. Brain Res. 52: 57-66.

Hamos, J. F., S. C. Van Horn, D. Raczkowski, D. J. Uhlrich, and S. M. Sherman (1985) Synaptic connectivity of a local circuit neurone in lateral geniculate nucleus of the cat. Nature 317:618-621.

Hamos, J. F., S. C. Van Horn, D. Raczkowski, and S. M. Sherman (1987) Synaptic circuits involving an individual retinogeniculate axon in the cat. J. Comp. Neurol. 259: 165-192.

Hanker, J. S., P. E. Yates, C. B. Metz, and A. Rustioni (1977) A new specific sensitive and non-carcinogenic agent for the demonstration of horseradish peroxidase. Histochem. J. 9: 789-792.

Harting, J. K., V. A. Casagrande, and J. T. Weber (1978) The projection of the primate superior colliculus upon the dorsal lateral geniculate nucleus: Autoradiographic demonstration of interlaminar distribution of tectogeniculate axons. Brain Res. 150: 593-599.

Harting, J. K., T. Hashikawa, and D. Van Lieshout (1986) Laminar distribution of tectal, parabigeminal and pretectal inputs to the primate dorsal lateral geniculate nucleus: Connectional studies in Galago crassicaudatus. Brain Res. 366: 358-363.

Hendrickson, A. E. (1972) Electron microscopic distribution of axoplasmic transport. J. Comp. Neurol. 144: 381-398.

Hendrickson, A. E., and P. Rakic (1977) Histogenesis and synaptogenesis in the dorsal lateral geniculate nucleus (LGd) of the fetal monkey brain. Anat. Rec. 187:602.

Hendrickson, A. E., M. P. Ogren. J. E. Vaughn, R. P. Barber, and J.-Y. Wu (1983) Light and electron microscopic immunocytochemical localization of glutamic acid decarboxylase in monkey geniculate complex: Evidence for gabaergic neurons and synapses. J. Neurosci. 3: $1245-1262$.

Henneman, E., and L. M. Mendell (1981) Functional organization of motorneuron pool and its inputs. In Iandbook of Physiologv. The Nervous System, Vol. 2, pp. 423-507.

Hess, D. T., and K. S. Rockland (1983) The distribution of cholinesterase and cytochrome oxidase within the dorsal lateral geniculate nucleus of the squirrel monkey. Brain Res. 289: 322-325.

Hirsch. J. C., A. Fourment, and M. E. Marc (1983) Sleep-related variations of membrane potential in the lateral geniculate body relay neurons of the cat. Brain Res. 259: 308-312.

Holdefer, R. N., T. T. Norton, and D. W. Godwin (1989) Effects of bicuculline on signal detectability in lateral geniculate nucleus relay cells. Brain Res. (in press).

Horton. J. C., and H. Sherk (1984) Receptive field properties in the cat's lateral geniculate nucleus in the absence of ON-center retinal input. J. Neurosci. 4: 374-380.

Humphrey, A. L., and R. E. Weller (1988) Structural correlates of functionally distinct $X$-cells in the lateral geniculate nucleus of the cat. J. Comp. Neurol. 268: 448-468.

Irwin, G. E., T. T. Norton, M. A. Sesma, and V. A. Casagrande (1986) W-like response properties of interlaminar zone cells in the lateral geniculate nucleus of a primate (Galago crassicaudatus). Brain Res. 362: 254-270.

Jones, E. G. (1975) Some aspects of the organization of the thalamic reticular complex. J. Comp. Neurol. 162: 285-308.

Jones, E. G., and T. P. S. Powell (1969) An electron microscopic study of the mode of termination of cortico-thalamic fibers within the sensory relay nuclei of the thalamus. Proc. R. Soc. London [Biol.] 172: $173-185$.

Kaas, J. H., M. F. Huerta, J. T. Weber, and J. K. Harting (1978) Patterns of retinal terminations and laminar organization of the lateral geniculate nucleus of primates. J. Comp. Neurol. 182: 517-554.

Lee, B. B., O. D. Creutzfeldt. and A. Elepfandt (1979) The responses of magno- and parvocellular cells of the monkey's lateral geniculate body to moving stimuli. Exp. Brain Res. 35: 547-557.

LeVay, S. (1971) On the neurons and synapses of the lateral geniculate nucleus of the monkey and the effects of eye enucleation. Z. Zellforsch. 113: 396-419. 
Lieberman, A. R. (1973) Neurons with presynaptic perikarya and presynaptic dendrites in the rat lateral geniculate nucleus. Brain Res. 59: 35-59.

Lieberman, A. R., and K. E. Webster (1974) Aspects of the synaptic organization of intrinsic neurons in the dorsal lateral geniculate nucleus. J. Neurocytol. 3: 677-710.

Lin, C.-S., and J. H. Kaas (1977) Projections from cortical visual areas 17,18 , and $\mathrm{MT}$ onto the dorsal lateral geniculate nucleus in owl monkeys. J. Comp. Neurol. 173: 457-474.

Livingston, M. S., and D. H. Hubel (1981) Effects of sleep and arousal in the processing of visual information in the cat. Nature 291: 554561.

Marrocco, R. T. (1976) Sustained and transient cells in monkey lateral geniculate nucleus: Conduction velocities and response properties. J. Neurophysiol. 39: 340-353.

Marrocco, R. T., and J. B. Brown (1975) Correlation of receptive field properties of monkey LGN cells with the conduction velocity of retinal afferent input. Brain Res. 92: 137-144.

Marrocco, R. T., and J. W. McClurkin (1979) Binocular interaction in the lateral geniculate nucleus of the monkey. Brain Res. 168: 633637.

Marrocco, R. T., J. W. McClurkin, and R. A. Young (1982) Spatial summation and conduction latency classification of cells of the lateral geniculate nucleus of macaques. J. Neurosci. 2: 1275-1291.

Mastronarde, D. M. (1987a) Two classes of single-input X-cells in cat lateral geniculate nucleus: I. Receptive-field properties and classification of cells. J. Neurophysiol. 57: 357-380.

Mastronarde, D. M. (1987b) Two classes of single-input X-cells in cat lateral geniculate nucleus: II. Retinal inputs and the generation of receptive field properties. J. Neurophysiol. 57: 381-413.

McCorley, R. W., O. Benoit, and G. Barrionuevo (1983) Lateral geniculate nucleus unitary discharge in sleep and waking: State- and rate-specific aspects. J. Neurophysiol. 50:798-818.

Montero, V. M. (1986a) Localization of gamma-aminobutyric acid (GABA) in type 3 cells and demonstration of their source to F2 terminals in the cat lateral geniculate nucleus: A Golgi-electron microscopic GABA-immunocytochemical study. J. Comp. Neurol. 254: 228-245.

Montero, V. M. (1986b) The interneuronal nature of GABAergic neurons in the lateral geniculate nucleus of the rhesus monkey: A combined HRP and GABA-immunocytochemical study. Exp. Brain Res. 64: 615-622.

Montero, V. M. (1987) Ultrastructural identification of synaptic terminals from the axons of Type 3 interneurons in the cat lateral geniculate nucleus. J. Comp. Neurol. 264: 268-283.

Montero, V. M., and G. L. Scott (1981) Synaptic terminals in the dorsal lateral geniculate nucleus from neurons of the thalamic reticular nucleus: A light and electron microscopic autoradiographic study. Neuroscience 6: 2561-2577.

Montero, V. M., and J. Zempel (1986) The proportion and size of GABA-immunoreactive neurons in the magnocellular and parvocellular layers of the lateral geniculate nucleus of rhesus monkey. Exp. Brain Res. 62: 215-223.

Morrison, J. H., and S. L. Foote (1986) Noradrenergic and serotoninergic innervation of cortical, thalamic, and tectal visual structures in Old and New World monkeys. J. Comp. Neurol. 243: 117-138.

Norden. J. J., and J. H. Kaas (1978) The identification of relay neurons in the dorsal lateral geniculate nucleus of monkeys using horseradish peroxidase. J. Comp. Neurol. 182: 707-726.

Norton, T. T., and V. A. Casagrande (1982) Laminar organization of receptive-field properties in lateral geniculate nucleus of Bush Baby (Galago crassicaudatus). J. Neurophysiol. 97: 715-741.

Ohara, P. T., A. J. Sefton, and A. R. Lieberman (1980) Mode of termination of afferents from the thalamic reticular nucleus in the dorsal lateral geniculate nucleus of the rat. Brain Res. 197: 503-506.

O'Leary, J. L., J. M. Smith, M. Tidwell, and A. B. Harris (1965) Synapses in the lateral geniculate nucleus of the primate. Neurology 15: 548-555.

Pasik, P., T. Pasik, I. Hámori, and P. Szentágothai (1973a) Golgi type II interneurons in the neuronal circuit of the monkey lateral geniculate nucleus. Exp. Brain Res. 17: 18-34.

Pasik, P., T. Pasik, J. Hámori, and P. Szentágothai (1973b) "Triadic" synapses and other articulations of interneurons in the lateral geniculate of rhesus monkeys. Trans. Am. Neurol. Assoc. 98: 293-295.

Pasik, P., T. Pasik, and J. Hámori (1976) Synapses between interneu- rons in the lateral geniculate nucleus of monkeys. Exp. Brain Res. 25: $1-13$

Pasik, P., T. Pasik, and J. Hámori (1986) A newly recognized element in the monkey dorsal lateral geniculate nucleus exhibiting both presynaptic and postsynaptic sites. J. Neurocytol. 15: 177-186.

Pecci-Saavedra, J., O. L. Vaccarezza, and T. A. Reader (1968) Ultrastructure of cells and synapses in the parvocellular portion of the cebus monkey lateral geniculate nucleus. $Z$. Zellforsch. 89: 462-477.

Rapisardi, S. (1981) Serial thin section analysis of retino-geniculate afferents in the dorsal lateral geniculate nucleus of the monkey. Neurosci. Lett. Suppl. 7: 51-52.

Rapisardi, S. C., and L. Lipsenthal (1984) Asymmetric and symmetric synaptic junctions in the dorsal lateral geniculate nucleus of cat and monkey. J. Comp. Neurol. 224: 415-424.

Rapisardi, S. C., and T. P. Miles (1984) Synaptology of the retinal afferent in the cat. J. Comp. Neurol. 223: 515-534.

Rapisardi, S. C., J. R. Wilson, and W. T. Chang (1986) Difference between lateral geniculate neurons (cat) with and without appendages: Retinal input patterns. Soc. Neurosci. Abstr. 12: 9.

Robson, J. A. (1983) The morphology of corticofugal axons to the dorsal lateral geniculate nucleus in the cat. J. Comp. Neurol. 216: 89103.

Robson, J. A., and W. C. Hall (1977) The organization of the pulvinar in the grey squirrel (Sciurus carolinesis). II. Synaptic organization and comparison with the dorsal lateral geniculate nucleus. J. Comp. Neurol. 173: $389-416$

Rodieck, R. W., and B. Dreher (1979) Visual suppression from nondominant eye in the lateral geniculate nucleus: A comparison of cat and monkey. Exp. Brain Res. 35: 465-477.

Saini, and L. Garey (1981) Morphology of neurons in the lateral geniculate nucleus of the monkey. A Golgi study. Exp. Brain Res. 42: $235-248$.

Sanderson, K. J., P. O. Bishop, and I. Darian-Smith (1971) The properties of the binocular fields of lateral geniculate neurons. Exp. Brain Res. 13: 178-207.

Schiller, P. H. (1982) Central connections of the retinal ON and OFF pathways. Nature 297: 580-583.

Schiller, P. H., and J. G. Malpeli (1977) Properties and tectal projections of monkey ganglion cells. J. Neurophysiol. 40: 428-445.

Schiller, P. H., and J. G. Malpeli (1978) Functional specificity of lateral geniculate nucleus laminae of the rhesus monkey. J. Neurophysiol 41: 788-794.

Schmielau, F., and W. Singer (1977) The role of visual cortex for binocular interactions in the cat lateral geniculate nucleus. Brain Res. 120: 354-361.

Shapley, R., and V. H. Perry (1986) Cat and monkey retinal ganglion cells and their visual functional roles. Trends Neurosci. 9: 229-235.

Shapley, R. M., E. Kaplan, and R. Soodak (1981) Spatial summation and contrast sensitivity of $\mathrm{X}$ - and $\mathrm{Y}$-cells in the lateral geniculate nucleus of the macaque. Nature 292: 543-545.

Shatz, C. J., and P. Rakic (1981) The genesis of efferent connections from the visual cortex of the fetal rhesus monkey. J. Comp. Neurol. 196: 287-307.

Sherman, S. M., and C. Koch (1986) The control of retinogeniculate transmission in the mammalian lateral geniculate nucleus. Fxp. Brain Res. 63: 1-20.

Sherman, S. M., J. R. Wilson, J. H. Kaas, and S. V. Webb (1976) Xand $Y$-cells in the dorsal lateral geniculate nucleus of the owl monkey (Aotus trivirgatus). Science 192: 475-477.

Sillito, A. M., and J. A. Kemp (1983) The influence of GABAergic inhibitory processes on the receptive field structure of $X$ and $Y$ cells in cat dorsal lateral geniculate nucleus (dLGN). Brain Res. 277: 6377.

Singer, W. (1977) Control of thalamic transmission by corticofugal and ascending reticular pathways in the visual system. Physiol. Rev. 57: $386-420$

Spatz, W. B., J. Tigges, and M. Tigges (1970) Subcortical projections, cortical associations and some intrinsic interlaminar connections of the striate cortex in the squirrel monkey (Saimiri). J. Comp. Neurol. 140: 155-174.

Stevens, J. K., and G. L. Gerstein (1978) A synaptic triad as the input to " $X$ " lateral geniculate cells. Soc. Neurosci. Abstr. 4: 647.

Szentágothai, J., J. Hámori, and T. Tömböl (1966) Degeneration and electron microscopic analysis of the synaptic glomeruli in the lateral geniculate body. Exp. Brain Res. 2: 283-301 
Torrealba, F., G. D. Partlow, and R. W. Guillery (1981) Organization of the projection from the superior colliculus to the dorsal lateral geniculate nucleus of the cat. Neuroscience $6: 1341-1360$.

Tsumoto, T., O. D. Creutzfeldt, and C. R. Hegendy (1978) Functional organization of the corticofugal system from visual cortex to lateral geniculate nucleus in the cat. Exp. Brain Res. 32: 345-364.

Weber, A. J., and R. E. Kalil (1987) Development of corticogeniculate synapses in the cat. J. Comp. Neurol. 264: 171-192.

Weber, J. T., M. F. Huerta, J. H. Kaas, and J. K. Harting (1983) The projection of the lateral geniculate nucleus of the squirrel monkey: Studies of the interlaminar zones and the S layers. J. Comp. Neurol. 213: 135-145.

Wiesel, T. N., and D. H. Hubel (1966) Spatial and chromatic interactions in the lateral geniculate body of the rhesus monkey. J. Neurophysiol. 29: 1115-1156.

Wilson, J. R. (1982) An electron microscopic comparison of the medial interlaminar nucleus and the A laminae in the dorsal lateral geniculate nucleus of the cat. J. Comp. Neurol. 212:89-101.

Wilson, J. R. (1986) Synaptic connections of relay and local circuit neurons in the monkey's dorsal lateral geniculate nucleus. Neurosci. Lett. 66: 79-84.

Wilson, J. R., and A. E. Hendrickson (1981) Neuronal and synaptic structure of the dorsal lateral geniculate nucleus in normal and monocularly deprived Macaca monkeys. J. Comp. Neurol. 197: 517-539.

Wilson, J. R., and A. E. Hendrickson (1988) Serotonergic axons in the monkey's lateral geniculate nucleus. Visual Neurosci. 1: 125-133.

Wilson, J. R., M. J. Friedlander, and S. M. Sherman (1984) Fine structural morphology of identified X-and Y-cells in the cat's lateral geniculate nucleus. Proc. R. Soc. London 221: 411-436.

Wilson, J. R., J. Bullier and T. T. Norton (1988) Signal-to-noise comparisons for $\mathrm{X}$ and $\mathrm{Y}$ cells in the retina and lateral geniculate nucleus of the cat. Exp. Brain Res. 70:399-405.

Winfield, D. A. (1980) The synaptic organization of glomeruli in the magnocellular and parvocellular laminae of the lateral geniculate nucleus in the monkey. Brain Res. 198: 55-62.

Winfield, D. A., K. C. Gatter, and T. P. S. Powell (1975) Certain connections of the visual cortex of the monkey shown by the use of horseradish peroxidase. Brain Res. 92: 456-461.

Wong, M. T. T. (1970) Somato-dendritic and dendro-dendritic synapses in squirrel monkey lateral geniculate nucleus. Brain Res. 20 : 135-139.

Wong-Riley, M. T. T. (1972) Neuronal and synaptic organization of the normal dorsal lateral geniculate nucleus of the squirrel monkey, Saimiri sciureus. J. Comp. Neurol. 144: 25-60. 